Draft VERSion July 24, 2018

Preprint typeset using $\mathrm{LAT}_{\mathrm{E}} \mathrm{X}$ style emulateapj v. 11/10/09

\title{
FORMATION OF DIFFERENT ISOTOPOMERS OF CHLORONIUM IN THE INTERSTELLAR MEDIUM
}

\author{
Liton Majumdar ${ }^{1}$, Ankan Das ${ }^{1}$, Sandip K. Chakrabarti ${ }^{2,1}$ \\ ${ }^{1}$ Indian Centre for Space Physics, Chalantika 43, Garia Station Rd., Kolkata, 700084, India and \\ ${ }^{2}$ S. N. Bose National Centre for Basic Sciences, Salt Lake, Kolkata, 700098, India \\ Draft version July 24, 2018
}

\begin{abstract}
Main focus of this paper is to explore the possibility of findings two deuterated isotopomers of $\mathrm{H}_{2} \mathrm{Cl}^{+}$(Chloronium) in and around the Interstellar Medium (ISM). Presence of Chloronium ion has recently been confirmed by Herschel Space Observatory's Heterodyne Instrument for the Far-Infrared (Neufeld et al. 2012). It observed para-chloronium towards six sources in the Galaxy. Existence of its deuterated isotopomers $\left(\mathrm{HDCl}^{+} \& \mathrm{D}_{2} \mathrm{Cl}^{+}\right)$are till date not discussed in the literature. We find that these deuterated gas phase ions could be destroyed by various ion-molecular reactions, dissociative recombination (DR) and by cosmic rays (CR). We compute all the Ion-molecular (polar) reaction rates by using the parameterized trajectory theory and the Ion-molecular (non-polar) reaction rates by using the Langevin theory. For DR and CR induced reactions, we adopt two well behaved rate formulas. We also include these rate coefficients into our large gas-grain chemical network to study the chemical evolution of these species around the outer edge of the cold dense cloud. In order to study spectral properties of chloronium ion and its two deuterated isotopomers, we have carried out quantum chemical simulations. We calculated ground state properties of these species by employing second order Moller-Plesset perturbation theory (MP2) along with quadruple-zeta correlation consistent (aug-ccpVQZ) basis set. Infrared and electronic absorption spectra of these species are calculated by using the same level of theory. MP2/aug-cc-pVQZ level of theory is used to report the different spectroscopic constants of these gas phase species. These spectroscopic constants are essential to predict rotational transitions of these species. Our predicted column densities of $\mathrm{D}_{2} \mathrm{Cl}^{+}, \mathrm{HDCl}^{+}$along with the spectral information may enable their future identification around outer edges of cold dark clouds.

Subject headings: Astrochemistry, spectra, ISM: molecules, ISM: abundances, ISM: evolution, methods: numerical
\end{abstract}

\section{INTRODUCTION}

Cologne Database for Molecular Spectroscopy (CDMS) catalog (Muller et al. 2001; Müller et al. 2005) keeps records on discovered molecules in interstellar medium (ISM). According this catalog, more than 170 molecules have been detected so far in the ISM. Among them, there are some simple halides like, such as, $\mathrm{HF}, \mathrm{CF}$, $\mathrm{AlF}, \mathrm{HCl}, \mathrm{HCl}^{+}, \mathrm{NaCl}, \mathrm{KCl}, \mathrm{AlCl}, \mathrm{MgCl}$ etc. Several works have been done in the past to model the chemistry of the chlorine-bearing molecules in both the diffuse and dense molecular clouds (Jura 1974; Dalgarno et al. 1974; van Dishoeck \& Black 1986; Schilke et al. 1995; Federman et al. 1995; Amin 1996; Neufeld \& Wolfire 2009). Various halogen elements such as fluorine and chlorine having solar abundances $\left(3.6 \times 10^{-8}\right.$ and $3.2 \times 10^{-7}$ respectively relative to total hydrogen nuclei (Asplund et al. 2009)) play an important role towards the formation of various hydrides in the ISM. Dissociation energy of most of the hydrides are less than that of the hydrogen molecule, only exceptions are the diatomic hydrides, such as, $\mathrm{HF}$ and diatomic hydride cations, such as, $\mathrm{HCl}^{+}$(Lis et al. 2010). Around an ISM, most of the halogen elements are biased to form hydrides (Neufeld et al. 2010). Huge abundances of HF and $\mathrm{H}_{2} \mathrm{Cl}^{+}$are observed around the diffuse molecular clouds (Neufeld et al. 2010; Sonnentrucker et al. 2010; Lis et al. 2010).

The ionization potential of chlorine is slightly less than

1 ankan.das@gmail.com that of the hydrogen and singly-ionized chlorine $\left(\mathrm{Cl}^{+}\right)$ can react exothermically with $\mathrm{H}_{2}$ to form $\mathrm{HCl}^{+}$. This $\mathrm{HCl}^{+}$further interacts with $\mathrm{H}_{2}$ to form $\mathrm{H}_{2} \mathrm{Cl}^{+}$. These features are already known by theory of thermo chemistry of these species. Since Choloronium ion does not react with hydrogen molecule, dissociative recombination appears to be its main destruction route. Chloronium ion could also be destroyed by reacting with $\mathrm{CO}$ molecule. Main product of these destruction routes is hydrogen chloride $(\mathrm{HCl})$. Theoretical modeling by considering the chlorine bearing molecules predicts that abundances of the Chloronium ions are significantly higher and could be observed. But surprisingly, before the launching of Herschel, among the $\mathrm{Cl}$ bearing molecules, only $\mathrm{H}^{35} \mathrm{Cl}$ and $\mathrm{H}^{37} \mathrm{Cl}$ were detected (Blake et al. 1985; Zmuidzinas et al. 1995; Schilke et al. 1995; Salez et al. 1996). Chemical modeling suggests that Chloronium ions could be very abundant around the diffuse interstellar medium. The detection of $\mathrm{H}_{2} \mathrm{Cl}^{+}$was first reported towards NGC 6334I and Sgr B2(S) using the HIFI instrument (de Graauw et al. 2010) aboard the Herschel Space Observatory (Pilbratt et al. 2010). A follow up study by Neufeld et al. (2012) also detected $\mathrm{H}_{2} \mathrm{Cl}^{+}$absorption towards Sgr A, W31C and detected Chloronium emission from two sources in the Orion Molecular Cloud 1 (the Orion Bar photodissociation region and Orion South condensation) and the young massive star AFGL 2591.

Despite these overwhelmingly significant observational evidences, till date, no deuterated forms of $\mathrm{H}_{2} \mathrm{Cl}^{+}$have been observed in the ISM. This motivates 
us to model the formation/destruction of different forms of deuterated $\mathrm{H}_{2} \mathrm{Cl}^{+}$in the ISM. Importance of interstellar grains in producing simpler molecules has been widely described by several authors such as Stantcheva et al. (2002); Hasegawa. Herbst \& Leung (1992): Chakrabarti et al. (2006a, b); Das et al. (2008a, b); Das, Acharyya \& Chakrabarti (2010); Das et al. (2011). These studies indicate that dusts could play a crucial role for deciding chemical compositions around any molecular cloud. In order to understand complete picture of how molecules are formed in or around an ISM, we used our large gas-grain chemical model (Das et al. 2013a; Majumdar et al. 2012, 2013a, b).

Majumdar et al. (2013a,b) \& Das et al. (2013b) performed quantum chemical simulations to find out various chemical properties of some interstellar species. In the current paper, we carry out a similar types of quantum chemical calculations to find out the spectral information (infrared, electronic and rotational) of different deuterated istotopomers of Chloronium ion. We have also provided detailed information about rotational transitions of these species (in the format of JPL catalog). Such a study would be extremely helpful for the identification of these species around ISMs.

The plan of this paper is the following: In Section 2, the models and the computational details are presented. Implications of the results are discussed in Section 3. Finally, in Section 4, we draw our conclusions. In Appendix A, we tabulate relevant parameters for rotational spectroscopy of one of the isotopomer of $\mathrm{H}_{2} \mathrm{Cl}^{+}$in the format of JPL catalog.

\section{COMPUTATIONAL DETAILS}

\subsection{Quantum chemical simulations and derived spectral parameters}

We study spectral properties of interstellar chloronium by first optimizing the geometry of chloronium using second order Moller-Plesset perturbation theory (MP2) along with aug-cc-PVQZ basis set. MP2 theory is a special case of more general many-body perturbation theory (Puzzarini, Stanton \& Gauss 2010). For calculations where only valence electrons are correlated (i.e., frozen core calculation), standard cc-pVXZ sets with $\mathrm{X}=\mathrm{D}, \mathrm{T}, \mathrm{Q}, 5$ and 6 are recommended (Puzzarini. Stanton \& Gauss 2010). Because of this, we use here aug-cc-pVQZ basis set along with MP2 method. Vibrational frequencies of $\mathrm{H}_{2} \mathrm{Cl}^{+}$and its two deuterated isotopomers; $\mathrm{D}_{2} \mathrm{Cl}^{+}$and $\mathrm{HDCl}^{+}$are computed by determining second derivative of energy with respect to Cartesian nuclear coordinates and then transforming into mass-weighted coordinates. This transformation is valid only at a stationary point.

Vibrational frequencies of these species in the ice phase are also obtained by using the same level of theory. Vibrational spectra of any chemical species are significantly affected by the type of solvent used in the simulation. In our modeling purpose, here we have used Polarizable Continuum Model (PCM) with integral equation formalism variant (IEFPCM) as a default Self-consistent Reaction Field (SCRF) method (Tomasi et al. . 2002; Tomasi. Mennucci \& Cami 2005; Tomasi. Mennucci \& Cances 1999; Pascual-Ahuir et al.
1994). SCRF method in Gaussian 09W program is used to perform calculations in presence of a solvent by placing the solute in a cavity within a solvent reaction field. Following Das et al. (2013b), here too we have considered simple as well as mixed ice. By simple ice, we mean ice made from water molecule only and by mixed ice, we mean the ice made from water, methanol and carbon dioxide. Observations around cold dense region of molecular cloud reveal that $\sim 90 \%$ of interstellar grain mantle could be covered by $\mathrm{H}_{2} \mathrm{O}, \mathrm{CH}_{3} \mathrm{OH}$ and $\mathrm{CO}_{2}$ (Keane et al. 2001). We have also carried out quantum chemical simulation (time dependent density functional theory) to find out electronic absorption spectrum of these species in the gas phase as well as simple ice and mixed ice phase using the IEFPCM model.

An important key for the successful identification of different forms of chloronium in the interstellar space depends on the availability of accurate predictions of spectroscopic constants (rotational and distortional constants). Our computed rotational spectral information for interstellar chloronium is based on equilibrium geometry obtained at MP2/aug-cc-pVQZ level, i.e., with the consideration of core correlation and vibrational corrections to the rotational constants. Centrifugal distortion constants are computed from harmonic and anharmonic force fields obtained at MP2/aug-cc-pVQZ levels of theory. In addition, computed components of dipole moment were used to predict relative intensities of rotational transitions. These spectroscopic constants are essential to predict spectrum of different forms of $\mathrm{H}_{2} \mathrm{Cl}^{+}$ and this can be done by following techniques described in Das et al. (2013b). It used Picket's 'SPCAT' program (Pickett et al. 1991) for this purpose. Two main files, namely, 'file.var' and 'file.int' are required for the SPCAT program. Specified format of these two files were explained in detail in Pickett et al. (1991). Information regarding rotational constants, quadrupole coupling constants and distortional constants are given in '.var' file. Contents of '.var' file could directly be generated from Gaussian 09 program. '.int' file is the intensity file and it is prepared according to the prescribed format of 'SPCAT program'. This file contains maximum and minimum number of rotational states, partition function, rotational temperature and dipole moment of the molecule.

\subsection{Chemical Modeling}

In order to study various forms of choloronium in an interstellar medium (ISM), we have developed a chemical model which includes gas phase as well as grain surface chemical network. Our gas phase chemical network consists of a network of Woodall et al. (2007) and deuterated network used in Das et al. (2013b). In addition, we include some deuterated reactions by following Roberts \& Millar (2000); Albertsson et al. (2013). We include certain new reactions for formation and destruction of various forms of choloronium and its related species. Our present gas phase chemical network consists of 6180 reactions and present surface chemical network consists of 285 reactions. Except molecular hydrogen and Helium, depletion of all gas phase neutral species onto the grain surface are considered with a sticking probability of unity. The reason for ignoring this for $\mathrm{H}_{2}$ and $\mathrm{He}$ is that according to Leitch \& Williams (1985), the sticking coefficient of $\mathrm{H}_{2} \sim 0$ and Roberts \& Millar (2000) 
argued that Helium would not stick to the grain at all. Following is the list of reactions which are considered in our network for the formation/destruction of deuterated isotopomers of chloronium ion.

$$
\begin{aligned}
& \mathrm{H}^{+}+\mathrm{DCl} \rightarrow \mathrm{DCl}^{+}+\mathrm{H} \\
& \mathrm{He}^{+}+\mathrm{DCl} \rightarrow \mathrm{Cl}^{+}+\mathrm{He}+\mathrm{D} \\
& \mathrm{C}^{+}+\mathrm{DCl} \rightarrow \mathrm{CCl}^{+}+\mathrm{D} \\
& \mathrm{CH}_{3}^{+}+\mathrm{DCl} \rightarrow \mathrm{H}_{2} \mathrm{CCl}^{+}+\mathrm{HD} \\
& \mathrm{NH}_{2} \mathrm{D}+\mathrm{CCl}^{+} \rightarrow \mathrm{HCNH}^{+}+\mathrm{DCl} \\
& \mathrm{H}_{2} \mathrm{O}+\mathrm{HDCl}^{+} \rightarrow \mathrm{DCl}+\mathrm{H}_{3} \mathrm{O}^{+} \\
& \mathrm{CO}+\mathrm{HDCl}^{+} \rightarrow \mathrm{DCl}+\mathrm{HCO}^{+} \\
& \mathrm{H}_{2}+\mathrm{DCl}^{+} \rightarrow \mathrm{HDCl}^{+}+\mathrm{H} \\
& \mathrm{H}_{3}^{+}+\mathrm{DCl} \rightarrow \mathrm{HDCl}^{+}+\mathrm{H}_{2} \\
& \mathrm{CH}_{5}^{+}+\mathrm{DCl} \rightarrow \mathrm{HDCl}^{+}+\mathrm{CH}_{4} \\
& \mathrm{HD}+\mathrm{DCl}^{+} \rightarrow \mathrm{D}_{2} \mathrm{Cl}^{+}+\mathrm{H} \\
& \mathrm{H}_{2} \mathrm{D}^{+}+\mathrm{DCl} \rightarrow \mathrm{D}_{2} \mathrm{Cl}^{+}+\mathrm{H}_{2} \\
& \mathrm{HD}_{2}^{+}+\mathrm{DCl} \rightarrow \mathrm{D}_{2} \mathrm{Cl}^{+}+\mathrm{HD} \\
& \mathrm{CH}_{4} \mathrm{D}^{+}+\mathrm{DCl} \rightarrow \mathrm{D}_{2} \mathrm{Cl}^{+}+\mathrm{CH}_{4} \\
& \mathrm{H}_{2} \mathrm{O}+\mathrm{D}_{2} \mathrm{Cl}^{+} \rightarrow \mathrm{DCl}+\mathrm{H}_{2} \mathrm{DO}^{+} \\
& \mathrm{CO}+\mathrm{D}_{2} \mathrm{Cl}^{+} \rightarrow \mathrm{DCl}+\mathrm{DCO}^{+} \\
& \mathrm{HD}+\mathrm{Cl}^{+} \rightarrow \mathrm{DCl}^{+}+\mathrm{H} \\
& \mathrm{D}_{2}+\mathrm{Cl}^{+} \rightarrow \mathrm{DCl}^{+}+\mathrm{D} \\
& \mathrm{H}_{2}+\mathrm{DCl}^{+} \rightarrow \mathrm{HDCl}^{+}+\mathrm{H} \\
& \mathrm{HD}+\mathrm{HCl}^{+} \rightarrow \mathrm{HDCl}^{+}+\mathrm{H} \\
& \mathrm{D}_{2}+\mathrm{HCl}^{+} \rightarrow \mathrm{HDCl}^{+}+\mathrm{D} \\
& \mathrm{H}_{2} \mathrm{D}^{+}+\mathrm{Cl} \rightarrow \mathrm{DCl}^{+}+\mathrm{H}_{2} \\
& \mathrm{HD}_{2}^{+}+\mathrm{Cl} \rightarrow \mathrm{DCl}^{+}+\mathrm{HD} \\
& \mathrm{D}_{3}^{+}+\mathrm{Cl} \rightarrow \mathrm{DCl}^{+}+\mathrm{D}_{2}
\end{aligned}
$$

A10

Reaction A1 is a charge exchange type reaction. Rate coefficient for this reaction is assumed to be similar to the rate coefficient adopted for $\mathrm{H}^{+}+\mathrm{HCl} \rightarrow \mathrm{HCl}^{+}+\mathrm{H}$ in Woodall et al. (2007). Reactions A2 - A24 are Ionneutral type reactions. According to Herbst (2006), rate coefficients for ion-molecular reactions can be determined by using capture theories (in which translational energy of reactants must only surpass a long-range centrifugal barrier for a reaction to occur). The collision rate coefficient between an ion and non-polar neutral molecule can be determined by using so-called Langevin collision rate;

$$
k=2 \pi e \sqrt{\alpha_{d} / \mu},
$$

where, $e$ is electronic charge, $\alpha_{d}$ is polarizabilty of neutral non-polar molecule, $\mu$ is reduced mass of reactants. But for polar neutral species, a complex situation arises due to attraction between a charge and a rotating permanent dipole moment. In these cases, extensive trajectory calculations have been carried out by $\mathrm{Su} \&$ Chesnavich (1982) to predict rate coefficients $\left(k_{\text {cap }}\right)$ of ion-polar molecule capture collisions. According to Woon \& Herbst (2009), Su-Chesnavich formula can be written in two different ways and both of which uses a parameter $x=\mu_{D} / \sqrt{(2 \alpha k T)}$ where $\mathrm{k}$ is Boltzman constant \& $\mathrm{T}$ is the temperature. The ion-dipole $\left(k_{c a p}\right)$ rates can be parameterized using following equations:

$$
k_{\text {cap }}=(0.4767 x+0.6200) k_{L},
$$

and

$$
k_{c a p}=\left[(x+0.5090)^{2} / 10.526+0.9754\right] k_{L} .
$$

Equation 2 is used if $x \geq 2$ and Eqn. 3 is used if $x<2$. Note that for $x=0$, it reduces to the Langevin expression. Alternatively, the expression can be written in powers of temperature T. For example, when $x \geq 2$,

$$
k_{c a p}=c_{1}+c_{2} T^{-1 / 2}
$$

where, $c_{1}=0.62 k_{L}$ and $c_{2}=\left(0.4767 \mu_{D} / \sqrt{(} 2 \alpha K\right) k_{L}$. If the second term in Eqn. 4 is much greater than the first term, the expression has $T^{-1 / 2}$ dependence which is used in both the UMIST and OSU databases. We took values of polarizability and dipole moments of neutral species by following Woon \& Herbst (2009). They optimized equilibrium structures at RCCSD $(\mathrm{T}) /$ aug-cc-pVTZ level of theory using finite field approach to obtain dipole moment and dipole polarizability components. According to their calculations, values of the polarizabilities $(\alpha)$ for $\mathrm{HCl}, \mathrm{H}_{2} \mathrm{O}, \mathrm{H}_{2}, \mathrm{CO}, \mathrm{NH}_{3}$ are to be $2.538,1.406,0.773$, 1.951 and $2.087 \mathrm{~A}^{3}$ respectively and values of the Dipole moments $\left(\mu_{D}\right)$ for $\mathrm{HCl}, \mathrm{H}_{2} \mathrm{O}, \mathrm{H}_{2}, \mathrm{CO}, \mathrm{NH}_{3}$ are to be $1.075,1.845,0,0.101,1.519$ Debye respectively. Now, computation of polarizability and dipole moments depend on the derivatives of electronic energy with respect to external electric field. This electronic energy is not dependent on the mass of the nuclei as calculations are based on Born-Oppenheimer approximation. But experimental difference arises mostly from difference in vibrationally averaged structure. In our case, polarizability and dipole moments of $\mathrm{HD}, \mathrm{D}_{2}, \mathrm{DCl}, \mathrm{NH}_{2} \mathrm{D}$ are assumed to be similar to their hydrogenated counter part. Plugging these values (polarizability and dipole moment of the neutral species and reduced mass of the reactants) in above equations, we calculated reaction rates for the ion-neutral reactions (A2-A24).

Molecular ions could be destroyed by the following dissociative recombination reactions:

$$
\begin{gathered}
\mathrm{DCl}^{+}+e^{-} \rightarrow C l+D, \\
\mathrm{D}_{2} \mathrm{Cl}^{+}+e^{-} \rightarrow C l+D+D, \\
\mathrm{D}_{2} \mathrm{Cl}^{+}+e^{-} \rightarrow \mathrm{DCl}+\mathrm{D}, \\
\mathrm{HDCl}^{+}+e^{-} \rightarrow \mathrm{Cl}+\mathrm{D}+\mathrm{H}, \\
\mathrm{HDCl}^{+}+e^{-} \rightarrow \mathrm{DCl}+\mathrm{H},
\end{gathered}
$$

In the absence of experimentally determined rate coefficients, following Neufeld \& Wolfire (2009), we use Eqns. $5 \& 6$ for computation of DR rate coefficients (A25-A29) for diatomic and triatomic molecular ions, namely,

$$
k=2 \times 10^{-7}(T / 300)^{-1 / 2} \mathrm{~cm}^{3} s^{-1},
$$

and

$$
k=1.2 \times 10^{-7}(T / 300)^{-0.85} \mathrm{~cm}^{3} s^{-1} .
$$


TABLE 1

INITIAL ABUNDANCES USED RELATIVE TO TOTAL HYDROGEN NUCLEI.

\begin{tabular}{|c|c|}
\hline Species & Abundance \\
\hline \hline $\mathrm{H}_{2}$ & $5.00 \times 10^{-01}$ \\
$\mathrm{He}$ & $1.00 \times 10^{-01}$ \\
$\mathrm{~N}$ & $2.14 \times 10^{-05}$ \\
$\mathrm{O}$ & $1.76 \times 10^{-04}$ \\
$\mathrm{H}_{3}^{+}$ & $1.00 \times 10^{-11}$ \\
$\mathrm{C}^{+}$ & $7.30 \times 10^{-05}$ \\
$\mathrm{~S}^{+}$ & $8.00 \times 10^{-08}$ \\
$\mathrm{Si}^{+}$ & $8.00 \times 10^{-09}$ \\
$\mathrm{Fe}^{+}$ & $3.00 \times 10^{-09}$ \\
$\mathrm{Na}^{+}$ & $2.00 \times 10^{-09}$ \\
$\mathrm{Mg}^{+}$ & $7.00 \times 10^{-09}$ \\
$\mathrm{P}^{+}$ & $3.00 \times 10^{-09}$ \\
$\mathrm{Cl}^{+}$ & $4.00 \times 10^{-09}$ \\
$\mathrm{e}^{-}$ & $7.31 \times 10^{-05}$ \\
$\mathrm{HD}$ & $1.6 \times 10^{-05}$ \\
\hline
\end{tabular}

Following the destruction pathways of $\mathrm{HCl}$ (Woodall et al. 2007), we have assumed that DCl could also be destroyed by Cosmic ray induced(CRPHOT) Photo reactions;

$$
\mathrm{DCl}+\mathrm{CRPHOT} \rightarrow \mathrm{Cl}+\mathrm{D} .
$$

The rate of Cosmic ray induced photo-reaction (A30) could be adopted as follows:

$$
k_{C R}(T)=\alpha(T / 300)^{\beta} \gamma /(1-\omega) s^{-1},
$$

where, cosmic-ray ionization rate is denoted by $\alpha$, photo reaction probability per cosmic ray ionization is denoted by $\gamma$ and $\omega$ denotes reflection coefficients of dust grain in far UV. Following reaction $\mathrm{HCl}+\mathrm{CRPHOT} \rightarrow \mathrm{H}+\mathrm{Cl}$ in Woodall et al. (2007), here too we assume that $\alpha=$ $1.3 \times 10^{-17}, \beta=0, \gamma=305$ and $\omega=0.6$.

$\mathrm{DCl}$ could also be dissociated by following interstellar photo reaction $(\mathrm{PHOTON})$;

$$
\mathrm{DCl}+\mathrm{PHOTON} \rightarrow \mathrm{Cl}+\mathrm{D} .
$$

The rate coefficient for the reaction A31 could be calculated by using following relation:

$$
k_{P h o t}=\alpha \exp \left(-\gamma A_{V}\right) s^{-1},
$$

where, $A_{V}$ is the visual extinction and $\gamma=1.8$ is used following the reaction $\mathrm{HCl}+\mathrm{PHOTON} \rightarrow \mathrm{Cl}+\mathrm{H}$ in Woodall et al. (2007).

In our model, we assume that gas and grains are coupled through accretion and thermal/cosmic ray evaporation processes. To model the environment of the outer edge of a dense interstellar cloud or a diffuse cloud, we use $\mathrm{T}=10 \mathrm{~K}, \mathrm{n}_{H}=10^{3}-10^{4} \mathrm{~cm}^{-3}, \mathrm{~A}_{V}=0.01-10$ magnitude. Following Roberts \& Millar (2000), in Table 1 , initial elemental abundances relative to the total hydrogen nuclei is shown. This type of initial abundances are often adopted for the cold \& dark cloud. All computed/estimated rate coefficients (A1-A31) are provided in Table 2 for $\mathrm{T}=10 \mathrm{~K}, \mathrm{~A}_{V}=10$.

\section{RESULTS AND DISCUSSIONS}

\subsection{Chemical properties}

Interstellar chloronium $\left(\mathrm{H}_{2} \mathrm{Cl}^{+}\right)$is an asymmetric top with $\mathrm{C}_{2 V}$ symmetry. We performed quantum chemical simulation (MP2/aug-cc-pVQZ level of theory) for geometry optimization and energy calculation of chloronium ion. Ground state energies of $\mathrm{H}_{2} \mathrm{Cl}^{+}$in gas and ice phases are found to be -460.55382 a.u, -460.67002 a.u. (1 atomic unit $=27.21 \mathrm{eV}$ ) respectively. Due to solute-solvent electrostatic interaction (dipole level), ground state energy in ice phase is found to be lower than ground state energy in gas phase. The solvent effect also brings changes in geometrical parameters of these species. Our results confirm that polarization of solute by continuum has important effects on absolute and relative solvation energies, which in turn changes the energy of respective species. The ground state energy of $\mathrm{D}_{2} \mathrm{Cl}^{+}$and $\mathrm{HDCl}^{+}$are found to be similar to the ground state energy of $\mathrm{H}_{2} \mathrm{Cl}^{+}$in gas and in ice phases. This is due to the fact that ground state energy and structure calculations are made by using BornOppenheimer approximation so isotopic mass is not a factor in the Hamiltonian. The dipole moment of chloronium in gas and in ice phases are found to be 1.98 Debye and 2.2024 Debye respectively. The dipole moment of chloronium has been estimated as 1.89 Debye in ab initio calculations performed by Müller (2008). According to Puzzarini, Stanton \& Gauss (2010), additional splitting in rotational spectrum is governed by nuclear quadrupole coupling of molecules. Moreover, according to them, quantum chemical calculations could be extremely helpful for fine structure analysis because it could provide electric-field gradient at corresponding nuclei. In Table 3 , we show a comparison of experiment and theoretical ground state quadrupole coupling constants of chlorine $\mathrm{H}_{2} \mathrm{Cl}^{+}$for Mp2/aug-cc-pVQZ level of theory. Also, for the first time, we provide quadrupole coupling constants of chlorine in $\mathrm{D}_{2} \mathrm{Cl}^{+}, \mathrm{HDCl}^{+}$in the same table.

\subsection{Chemical evolution and deuterium enrichment}

In Fig. 1, chemical evolution of chloronium ion and related species are shown. To mimic the interstellar scenario, we consider $\mathrm{n}_{H}=10^{4} \mathrm{~cm}^{-3}, \mathrm{~A}_{V}=10$ and $\mathrm{T}=10 \mathrm{~K}$. It is assumed that initially all deuteriums are locked in the form of $\mathrm{HD}$. Initial abundances of $\mathrm{HD}$ and $\mathrm{H}_{2}$ are taken to be $1.6 \times 10^{-5}$ and 0.5 respectively (Table 1 ) with respect to total number of hydrogen nuclei. This implies an initial fractionation ratio of $3.2 \times 10^{-5}$. Unless otherwise stated, we use this initial fractionation ratio in all our simulations. In our gas-grain model, we assume that all the neutral species could be depleted to icy grain with a sticking coefficient of unity. Depleted species are allowed to populate the gas phase via thermal evaporation 
TABLE 2

Formation/DESTRUCTION OF DEUTERATED CHLORONIUM IONS AND RELATED SPECIES

\begin{tabular}{|c|c|c|}
\hline Reaction & Reaction Type & Rate coefficients \\
\hline$\overline{H^{+}+D C l \rightarrow D C l^{+}+H(\mathrm{~A} 1)}$ & Charge Exchange & $1.1 \times 10^{-10} \mathrm{~cm}^{3} \mathrm{~s}^{-1}$ \\
\hline $\mathrm{He}^{+}+\mathrm{DCl} \rightarrow \mathrm{Cl}^{+}+\mathrm{He}+\mathrm{D}(\mathrm{A} 2)$ & Ion-neutral & $1.8 \times 10^{-8} \mathrm{~cm}^{3} \mathrm{~s}^{-1}$ \\
\hline$C^{+}+D C l \rightarrow C C l^{+}+D(\mathrm{~A} 3)$ & Ion-neutral & $8.3 \times 10^{-10} \mathrm{~cm}^{3} \mathrm{~s}^{-1}$ \\
\hline $\mathrm{CH}_{3}^{+}+\mathrm{DCl} \rightarrow \mathrm{H}_{2} \mathrm{CCl}^{+}+\mathrm{HD}(\mathrm{A} 4)$ & Ion-neutral & $7.7 \times 10^{-09} \mathrm{~cm}^{3} \mathrm{~s}^{-1}$ \\
\hline $\mathrm{NH}_{2} \mathrm{D}^{+} \mathrm{CCl}^{+} \rightarrow \mathrm{HCNH}^{+}+\mathrm{DCl}$ (A5) & Ion-neutral & $9.5 \times 10^{-09} \mathrm{~cm}^{3} \mathrm{~s}^{-1}$ \\
\hline $\mathrm{H}_{2} \mathrm{O}+\mathrm{HDCl}^{+} \rightarrow \mathrm{DCl}+\mathrm{H}_{3} \mathrm{O}^{+}(\mathrm{A} 6)$ & Ion-neutral & $1.2 \times 10^{-08} \mathrm{~cm}^{3} \mathrm{~s}^{-1}$ \\
\hline $\mathrm{CO}+\mathrm{HDCl}^{+} \rightarrow \mathrm{DCl}^{+} \mathrm{HCO}^{+}(\mathrm{A} 7)$ & Ion-neutral & $2.5 \times 10^{-10} \mathrm{~cm}^{3} \mathrm{~s}^{-1}$ \\
\hline $\mathrm{H}_{2}+\mathrm{DCl}^{+} \rightarrow \mathrm{HDCl}^{+}+H(\mathrm{~A} 8)$ & Ion-neutral & $1.5 \times 10^{-09} \mathrm{~cm}^{3} \mathrm{~s}^{-1}$ \\
\hline $\mathrm{H}_{3}^{+}+\mathrm{DCl} \rightarrow \mathrm{HDCl}^{+}+\mathrm{H}_{2}(\mathrm{~A} 9)$ & Ion-neutral & $1.5 \times 10^{-08} \mathrm{~cm}^{3} \mathrm{~s}^{-1}$ \\
\hline $\mathrm{CH}_{5}^{+}+\mathrm{DCl} \rightarrow \mathrm{HDCl}^{+}+\mathrm{CH}_{4}(\mathrm{~A} 10)$ & Ion-neutral & $7.3 \times 10^{-09} \mathrm{~cm}^{3} \mathrm{~s}^{-1}$ \\
\hline $\mathrm{HD}+\mathrm{DCl}^{+} \rightarrow \mathrm{D}_{2} \mathrm{Cl}^{+}+\mathrm{H}(\mathrm{A} 11)$ & Ion-neutral & $1.2 \times 10^{-09} \mathrm{~cm}^{3} \mathrm{~s}^{-1}$ \\
\hline $\mathrm{H}_{2} \mathrm{D}^{+}+\mathrm{DCl} \rightarrow \mathrm{D}_{2} \mathrm{Cl}^{+}+\mathrm{H}_{2}(\mathrm{~A} 12)$ & Ion-neutral & $1.3 \times 10^{-08} \mathrm{~cm}^{3} \mathrm{~s}^{-1}$ \\
\hline $\mathrm{HD}_{2}^{+}+\mathrm{DCl} \rightarrow \mathrm{D}_{2} \mathrm{Cl}^{+}+\mathrm{HD}(\mathrm{A} 13)$ & Ion-neutral & $1.2 \times 10^{-08} \mathrm{~cm}^{3} \mathrm{~s}^{-1}$ \\
\hline $\mathrm{CH}_{4} \mathrm{D}^{+}+\mathrm{DCl} \rightarrow \mathrm{D}_{2} \mathrm{Cl}^{+}+\mathrm{CH}_{4}(\mathrm{~A} 14)$ & Ion-neutral & $7.2 \times 10^{-09} \mathrm{~cm}^{3} \mathrm{~s}^{-1}$ \\
\hline $\mathrm{H}_{2} \mathrm{O}+\mathrm{D}_{2} \mathrm{Cl}^{+} \rightarrow \mathrm{DCl}+\mathrm{H}_{2} \mathrm{DO}^{+}(\mathrm{A} 15)$ & Ion-neutral & $1.2 \times 10^{-08} \mathrm{~cm}^{3} \mathrm{~s}^{-1}$ \\
\hline $\mathrm{CO}+\mathrm{D}_{2} \mathrm{Cl}^{+} \rightarrow \mathrm{DCl}+\mathrm{DCO}^{+}(\mathrm{A} 16)$ & Ion-neutral & $2.5 \times 10^{-10} \mathrm{~cm}^{3} \mathrm{~s}^{-1}$ \\
\hline $\mathrm{HD}+\mathrm{Cl}^{+} \rightarrow \mathrm{DCl}^{+}+\mathrm{H}(\mathrm{A} 17)$ & Ion-neutral & $1.2 \times 10^{-09} \mathrm{~cm}^{3} \mathrm{~s}^{-1}$ \\
\hline$D_{2}+C l^{+} \rightarrow D C l^{+}+D(\mathrm{~A} 18)$ & Ion-neutral & $1.1 \times 10^{-09} \mathrm{~cm}^{3} \mathrm{~s}^{-1}$ \\
\hline $\mathrm{H}_{2}+\mathrm{DCl}^{+} \rightarrow \mathrm{HDCl}^{+}+\mathrm{H}(\mathrm{A} 19)$ & Ion-neutral & $1.5 \times 10^{-09} \mathrm{~cm}^{3} \mathrm{~s}^{-1}$ \\
\hline $\mathrm{HD}+\mathrm{HCl}^{+} \rightarrow \mathrm{HDCl}^{+}+\mathrm{H}(\mathrm{A} 20)$ & Ion-neutral & $1.2 \times 10^{-09} \mathrm{~cm}^{3} \mathrm{~s}^{-1}$ \\
\hline $\mathrm{D}_{2}+\mathrm{HCl}^{+} \rightarrow \mathrm{HDCl}^{+}+\mathrm{D}(\mathrm{A} 21)$ & Ion-neutral & $1.1 \times 10^{-09} \mathrm{~cm}^{3} \mathrm{~s}^{-1}$ \\
\hline $\mathrm{H}_{2} \mathrm{D}^{+}+\mathrm{Cl} \rightarrow \mathrm{DCl}^{+}+\mathrm{H}_{2}(\mathrm{~A} 22)$ & Ion-neutral & $1.0 \times 10^{-09} \mathrm{~cm}^{3} \mathrm{~s}^{-1}$ \\
\hline $\mathrm{HD}_{2}^{+}+\mathrm{Cl} \rightarrow \mathrm{DCl}^{+}+\mathrm{HD}(\mathrm{A} 23)$ & Ion-neutral & $1.0 \times 10^{-09} \mathrm{~cm}^{3} \mathrm{~s}^{-1}$ \\
\hline$D_{3}^{+}+C l \rightarrow D C l^{+}+D_{2}(\mathrm{~A} 24)$ & Ion-neutral & $1.0 \times 10^{-09} \mathrm{~cm}^{3} \mathrm{~s}^{-1}$ \\
\hline $\mathrm{DCl}^{+}+e^{-} \rightarrow \mathrm{Cl}+\mathrm{D}(\mathrm{A} 25)$ & Dissociative Recombination & $6.0 \times 10^{-6} \mathrm{~s}^{-1}$ \\
\hline $\mathrm{D}_{2} \mathrm{Cl}^{+}+e^{-} \rightarrow \mathrm{Cl}+\mathrm{D}+\mathrm{D}(\mathrm{A} 26)$ & Dissociative Recombination & $1.2 \times 10^{-5} s^{-1}$ \\
\hline $\mathrm{D}_{2} \mathrm{Cl}^{+}+e^{-} \rightarrow \mathrm{DCl}+\mathrm{D}(\mathrm{A} 27)$ & Dissociative Recombination & $1.2 \times 10^{-5} \mathrm{~s}^{-1}$ \\
\hline $\mathrm{HDCl}^{+}+e^{-} \rightarrow \mathrm{Cl}+\mathrm{D}+\mathrm{H}(\mathrm{A} 28)$ & Dissociative Recombination & $1.2 \times 10^{-5} s^{-1}$ \\
\hline $\mathrm{HDCl}^{+}+e^{-} \rightarrow \mathrm{DCl}+\mathrm{H}(\mathrm{A} 29)$ & Dissociative Recombination & $1.2 \times 10^{-5} \mathrm{~s}^{-1}$ \\
\hline $\mathrm{DCl}+\mathrm{CRPHOT} \rightarrow \mathrm{Cl}+\mathrm{D}(\mathrm{A} 30)$ & Cosmic ray induced Photodissociation & $9.9 \times 10^{-15} s^{-1}$ \\
\hline $\mathrm{DCl}+\mathrm{PHOTON} \rightarrow \mathrm{Cl}+\mathrm{D}(\mathrm{A} 31)$ & Photo-dissociation & $1.7 \times 10^{-17} \mathrm{~s}^{-1}$ \\
\hline
\end{tabular}

TABLE 3

Theoretical and Experimental quadrupole coupling Constants of Chlorine in $\mathrm{H}_{2} \mathrm{CL}^{+}, \mathrm{D}_{2} \mathrm{CL}^{+}, \mathrm{HDCl}^{+}$.

\begin{tabular}{|c|c|c|c|}
\hline Species & Constants & $\begin{array}{c}\text { Theoretical values } \\
\text { in MHz }\end{array}$ & $\begin{array}{c}\text { Experimental values } \\
\text { in } \mathrm{MHz}^{a}\end{array}$ \\
\hline \hline \multirow{3}{*}{$\mathbf{H}_{2} \mathbf{C l}^{+}$} & $\chi_{a a}$ & -51.8851 & -53.44 \\
& $\chi_{b b}$ & -14.3463 & -15.71 \\
& $\chi_{c c}$ & 66.2314 & 69.15 \\
& $\chi_{a b}$ & -0.4689 & - \\
\hline \multirow{3}{*}{$\mathbf{H D C l}^{+}$} & $\chi_{a a}$ & -39.2014 & - \\
& $\chi_{b b}$ & -27.1076 & - \\
& $\chi_{c c}$ & 66.3090 & - \\
& $\chi_{a b}$ & 17.4213 & - \\
\hline \multirow{3}{*}{$\mathbf{D}_{2} \mathbf{C l}^{+}$} & $\chi_{a a}$ & -51.8863 & - \\
& $\chi_{b b}$ & -14.3470 & - \\
& $\chi_{c c}$ & 66.2333 & - \\
\hline \multicolumn{3}{|c|}{$\chi_{a b}$ Saito \& Yamamoto $(1988)$} \\
\hline
\end{tabular}

and cosmic ray evaporation processes. Due to depletion of neutral species, rate of production of their relative ions are decreased. Dissociative recombination processes then lead to destruction of these ionic species. As a result, abundances of these ions are decreased. In our simulation, we evolved our chemical code till a time comparable to the life time of a generic molecular cloud ( $\sim 10^{7}$ years). From Fig. 1, it is clear that most of the species attain peak values near $\sim 10^{5}$ years. In the literature, a number of theoretical models attempted to find time variation of physical properties of protostars since the beginning of gravitational collapse (Smith 1998; Myers et al. 1998). Time sequence of evolutionary stages determined by various models are more or less similar but their estimates of absolute ages vary significantly (Emprechtinger et al.
2008). According to Froebrich et al. (2005), the absolute age for Class 0/I borderline objects, for example, varies between $10^{4}$ and a few times $10^{5}$ years. Our simulation results in Fig. 1 shows that within this time frame, some species will attain peak values. It is also evident that one of the isotopomers of $\mathrm{H}_{2} \mathrm{Cl}^{+}$(i.e., $\mathrm{HDCl}^{+}$from Fig. 1 ) is reasonably abundant within this time frame of collapse. So it is expected to be observed with ALMA, for example.

Following Shalabiea \& Greenberg (1994) and Das et al. (2011), the column density of a species could be calculated using the following relation:

$$
N(A)=n_{H} x_{i} R,
$$

where, $\mathrm{n}_{H}$ is the total hydrogen number density, $\mathrm{x}_{i}$ is the 


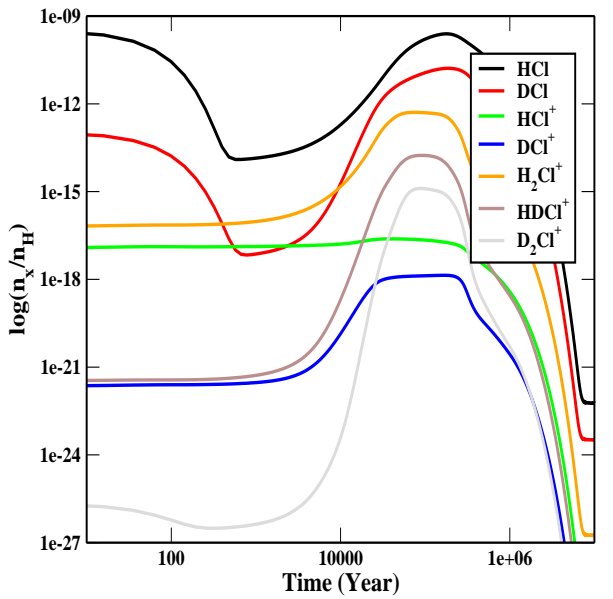

FIG. 1. - Time evolution of the Chloronium ion and its related species.

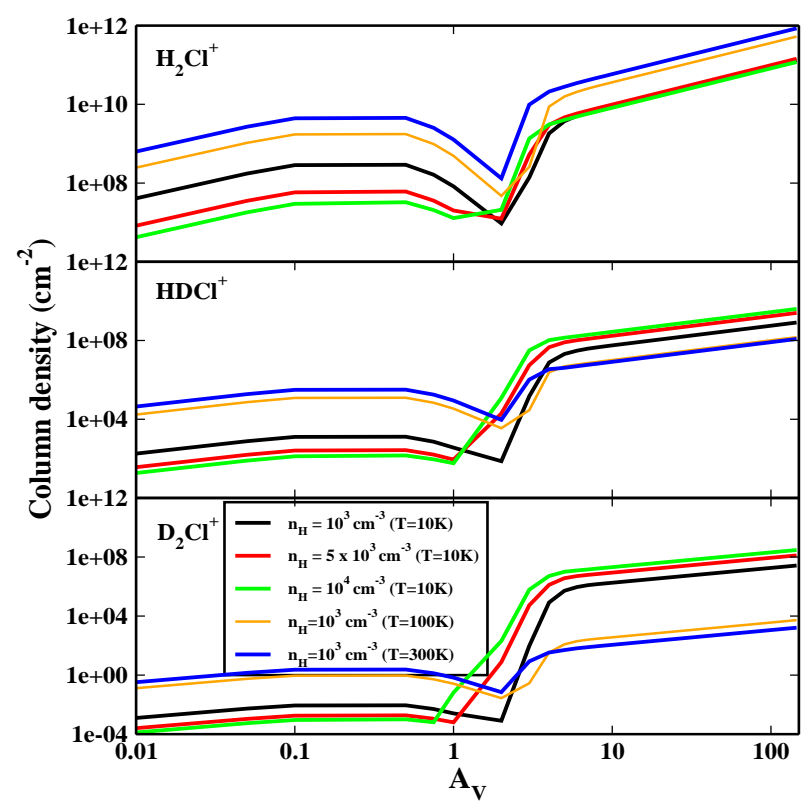

FIG. 2.- Variation of peak column densities with visual extinction parameter $\left(\mathrm{A}_{V}\right)$.

abundance of the $\mathrm{i}^{\text {th }}$ species and $R$ is the path length along the line of sight $\left(=\frac{1.6 \times 10^{21} \times A_{V}}{n_{H}}\right)$. According to Lis et al. (2010), $\mathrm{H}_{2} \mathrm{Cl}^{+}$is predicted to be the most abundant in those environments where ultraviolet radiation is strong (i.e., in diffuse clouds, or near surfaces of dense clouds that are illuminated by nearby $\mathrm{O}$ and $\mathrm{B}$ stars). In Fig. 2, we mimic these features by varying visual extinction parameter $\left(\mathrm{A}_{V}\right)$ from 0.1 to 145 . This high value of visual extinction $\left(A_{V}=145\right)$ could be used for W33A Allamandola, Sandford \& Tielens 1992). Variation of peak column densities of chloronium ion and its isotopomers are shown for different number density clouds $\left(10^{3}-10^{4} \mathrm{~cm}^{-3}\right)$. Abundance of $\mathrm{H}_{2} \mathrm{Cl}^{+}$roughly remains constant beyond $A_{V}=5$. From Eqn. 9 it is clear that the column density is directly proportional to $A_{V}$. As the abundance $\left(x_{i}\right)$ remains constant be-

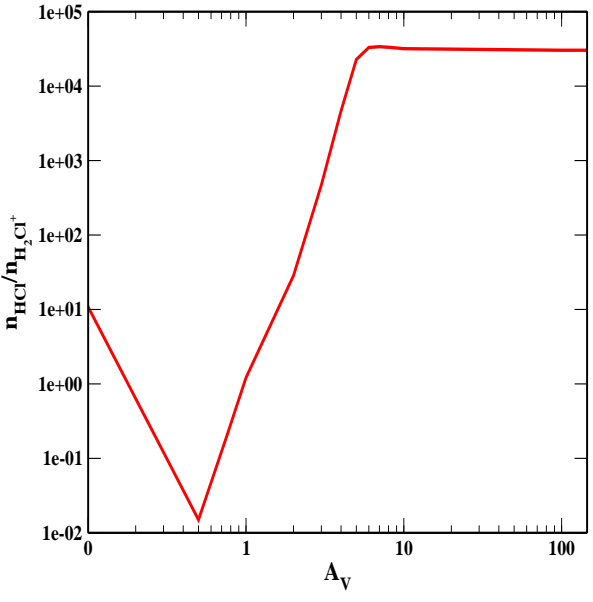

FIG. 3.- Variation of $\mathrm{HCl} / \mathrm{H}_{2} \mathrm{Cl}^{+}$column density ratio with $\mathrm{A}_{V}$

yond $A_{V}=5$, peak column densities increase linearly. For $\mathrm{A}_{V}<4$, peak column densities are heavily affected. Column densities are maximum around heavily shielded region $\left(A_{V}>4\right)$. Lis et al. (2010) computed column density of $\mathrm{H}_{2} \mathrm{Cl}^{+}$to be $2.2-3.4 \times 10^{13} \mathrm{~cm}^{-2}$ along NGC $6334 \mathrm{I}$ by assuming $5 \mathrm{~K}$ excitation temperature. Neufeld \& Wolfire (2009) identified $\mathrm{H}_{2} \mathrm{Cl}^{+}$around photo dissociation regions. According to their prediction, column density of $\mathrm{H}_{2} \mathrm{Cl}^{+}$around a photo dissociation region $\left(n_{H} \sim 10^{4} \mathrm{~cm}^{-3}, \kappa_{U V} \sim 10^{4}\right)$ would be $\sim 2.6 \times 10^{11}$ $\mathrm{cm}^{-2} \cdot \kappa_{U V}$ is the UV radiation field which is normalized with respect to the mean interstellar value by Draine (1978). Neufeld \& Wolfire (2009) also predicted column density of choloronium $\sim 3 \times 10^{11} \mathrm{~cm}^{-2}$ for the conditions which could be applicable to the environment of Orion $\operatorname{Bar}$ PDR $\left(\mathrm{n}_{H} \sim 6 \times 10^{4} \mathrm{~cm}^{-3}\right.$ and $\left.\kappa_{U V} \sim 3 \times 10^{4}\right)$. Their predicted column density was also 100 times smaller than what is found in recent observation by Lis et al. (2010). Neufeld et al. (2012) mentioned that this theoretically predicted value should not be compared directly with the observed values because theoretical prediction was for the perpendicular column density whereas Orion Bar PDR was observed nearly edge-on. They expect that geometrical enhancement in the observed value of the column density by a factor of 4 could be possible. In our case, we find a peak column density of $\mathrm{H}_{2} \mathrm{Cl}^{+} \sim 1.3 \times 10^{11}$ $\mathrm{cm}^{-2}$ in between $A_{V}=0.1-145, n_{H}=10^{3}-10^{4} \mathrm{~cm}^{-3}$ and $T=10 \mathrm{~K}$. We also carried out our simulation at higher temperature to find out effects of temperature on the formation of choloronium ion. For this case, we assumed $\mathrm{n}_{H}=10^{3} \mathrm{~cm}^{-3}$ and varied visual extinction $\left(A_{V}\right)$ in between $0.1-145$ for temperature $100 \mathrm{~K}$ and $300 \mathrm{~K}$ respectively (Fig. 2). From Fig. 2, it is evident that column density of choloronium ion increases with temperature and we have the maximum column density of $8.49 \times 10^{11} \mathrm{~cm}^{-2}$ at $300 \mathrm{~K}$. Column densities of deuterated forms of choloronium ion are also heavily affected by increase in temperature. For $A_{V}<2$, column densities of these deuterated ions increases whereas for $A_{V}>2$ they are found to decrease when compared to the $\mathrm{T}=10 \mathrm{~K}$ case.

Lis et al. (2010) derived $\mathrm{HCl} / \mathrm{H}_{2} \mathrm{Cl}^{+}$column density ratios to be in the range $\sim 1-10$, for diffuse and dense photon dominated regions (PDRs). In Fig. 3, we show variation of $\mathrm{HCl} / \mathrm{H}_{2} \mathrm{Cl}^{+}$column density ratio with $\mathrm{A}_{V}$. For $\mathrm{A}_{V}<2$ (i.e., for the strong radiation field), our 


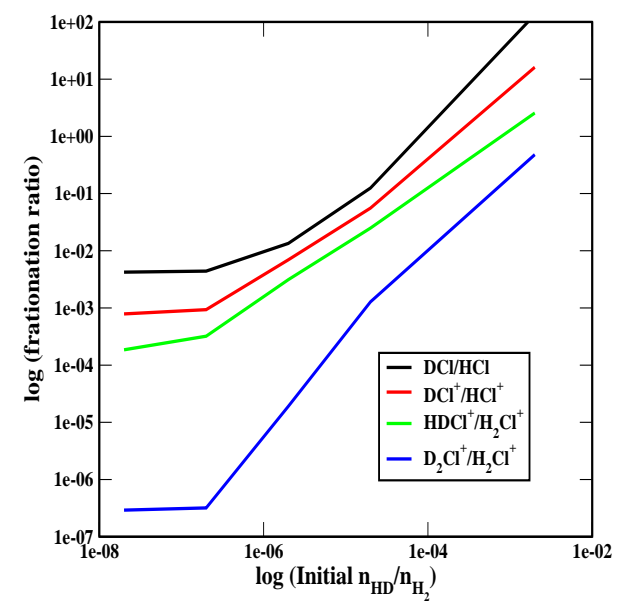

FIG. 4.- Variation of fractionation ratio with initial $\mathrm{HD} / \mathrm{H}_{2}$ ratio

results are in line with observation. For this case, we assumed $n_{H}=10^{4} \mathrm{~cm}^{-3}, T=10 \mathrm{~K}$, and $\mathrm{HCl} / \mathrm{H}_{2} \mathrm{Cl}^{+}$ column density ratio was taken after the simulation time scale of $\sim 10^{7}$ year.

In Fig. 4, we show variation of fractionation ratio of $\mathrm{HCl}, \mathrm{HCl}^{+}$and $\mathrm{H}_{2} \mathrm{Cl}^{+}$with initial $n_{H D / H_{2}}$ ratio. For this case, we assumed $n_{H}=10^{4} \mathrm{~cm}^{-3}, A_{V}=10$ and $T=10 \mathrm{~K} . \mathrm{HCl}$ and $\mathrm{HCl}^{+}$are found to be heavily fractionated, always crossing elemental $\mathrm{D} / \mathrm{H}$ ratio $\left(\sim 10^{-5}\right.$, Linsky et al., 1995). It is interesting to note that in our simulations, $\mathrm{HDCl}^{+} / \mathrm{H}_{2} \mathrm{Cl}^{+}$column density ratio is always above the elemental $\mathrm{D} / \mathrm{H}$ ratio . Fractionation ratio of $\mathrm{D}_{2} \mathrm{Cl}^{+}$molecule crossing the elemental $\mathrm{D} / \mathrm{H}$ ratio beyond initial $n_{H D / H_{2}}$ ratio $10^{-6}$. As $\mathrm{H}_{2} \mathrm{Cl}^{+}$molecule is heavily fractionated, we strongly suggest to look for $\mathrm{HDCl}^{+}$molecules in the same molecular clouds where $\mathrm{H}_{2} \mathrm{Cl}^{+}$molecule was already been observed.

\subsection{Spectral Analysis}

We now turn to spectral properties of $\mathrm{H}_{2} \mathrm{Cl}^{+}$and two of its isotopomers. For vibrational spectra, we compute infrared peak positions with their absorbance in gas phase as well as in water ice and mixed ice phases. In Table 4 , we present these for $\mathrm{H}_{2} \mathrm{Cl}^{+}$and two of its isotopomers, namely, $\mathrm{D}_{2} \mathrm{Cl}^{+}$and $\mathrm{HDCl}^{+}$. We find that the most intense mode of $\mathrm{H}_{2} \mathrm{Cl}^{+}$in the gas phase appears nearly at $2779.83 \mathrm{~cm}^{-1}$. This peak is shifted in the ice phase (water ice) by nearly $42 \mathrm{~cm}^{-1}$ and appears at $2822.06 \mathrm{~cm}^{-1}$. The second strongest peak in the gas phase appears at $2789.60 \mathrm{~cm}^{-1}$. It is also shifted in the ice phase. To have a more realistic condition, instead of only the water ice, we have considered a mixed ice mantle, which contains $70 \%$ water, $20 \%$ methanol and $10 \% \mathrm{CO}_{2}$ molecules (Keane et al. 2001; Das et al. 2011; Majumdar et al. 2013a, b; Das et al. 2013b). Gaussian $09 \mathrm{~W}$ program uses a dielectric constant of water to be $\sim 78.5$. For the case of mixed ice, we put the dielec-

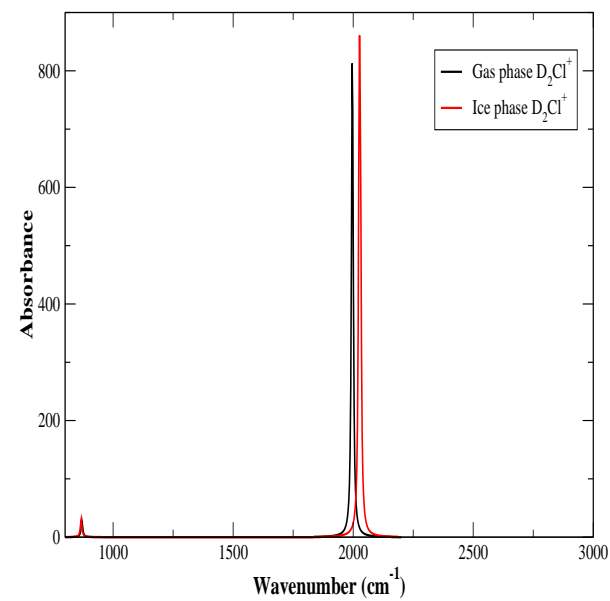

FIG. 5.- Infrared spectrum of $\mathrm{D}_{2} \mathrm{Cl}^{+}$in gas as well as in ice phase.

tric constant of the medium to be 61 , which is calculated by taking an weighted average of the dielectric constants of $\mathrm{H}_{2} \mathrm{O}, \mathrm{CH}_{3} \mathrm{OH}$ and $\mathrm{CO}_{2}$. We note that the most intense peak in gas phase is shifted in mixed ice also (Table 4). Isotope effects on chemical shifts is caused by differences in vibrational modes due to different isotope masses. Each of the $\mathrm{H}_{2} \mathrm{Cl}^{+}, \mathrm{D}_{2} \mathrm{Cl}^{+}$and $\mathrm{HDCl}^{+}$ molecules has a unique spectrum because substitution of isotope changes reduced mass of corresponding molecule. We find that the most intense mode of $\mathrm{D}_{2} \mathrm{Cl}^{+}$in gas phase appears at $1995.63 \mathrm{~cm}^{-1}$. This peak is shifted in ice phase by $29.82 \mathrm{~cm}^{-1}$, i.e., at $2025.45 \mathrm{~cm}^{-1}$. The second strongest peak in gas phase which appears at 1998.19 $\mathrm{cm}^{-1}$ is also shifted in ice phase and appears at 2030.55 $\mathrm{cm}^{-1}$. The most intense peak in gas phase is similarly shifted in mixed solvated grain. Infrared peak positions with their absorbance in gas phase as well as in ice and mixed ice phases are marked for $\mathrm{D}_{2} \mathrm{Cl}^{+}$and $\mathrm{HDCl}^{+}$in Table 4. In Fig. 5 and in Fig. 6, we show how the isotopic substitution $\left(\mathrm{D}_{2} \mathrm{Cl}^{+}\right.$and $\left.\mathrm{HDCl}^{+}\right)$plays a part in vibrational progressions of $\mathrm{H}_{2} \mathrm{Cl}^{+}$in gas phase and in ice phase. Our results clearly show differences between spectroscopic parameters computed for interstellar chloronium ion in gas phase and in ice phase. These differences can be explained due to electrostatic effects that are often much less important for species placed in a solvent with high dielectric constant than they are in gas phase (Foresman \& Frisch 1996).

In Table 5 , we summarize our calculated theoretical values of rotational and quartic centrifugal distortion constants for $\mathrm{H}_{2} \mathrm{Cl}^{+}, \mathrm{D}_{2} \mathrm{Cl}^{+}$and $\mathrm{HDCl}^{+}$in gas phase. Calculated constants are corrected for each vibrational state as well as vibrationally averaged structures. MP2/aug-cc-pVQZ level of theory has been used to perform these calculations for gas phase $\mathrm{H}_{2} \mathrm{Cl}^{+}, \mathrm{D}_{2} \mathrm{Cl}^{+}$and $\mathrm{HDCl}^{+}$. We compare our calculated spectroscopic constants (A, B, C, D JK ) of $\mathrm{H}_{2} \mathrm{Cl}^{+}$with Saito \& Yamamoto (1988) in Table 5. In order to summarize the outcome of our calculations about rotational spectroscopy, we prepare our spectral information for one of the isotopologues of $\mathrm{H}_{2} \mathrm{Cl}^{+}\left(\mathrm{HDCl}^{+}\right)$as per guidelines of JPL (Table A1 of Appendix A). Computed transitions are falling in be- 


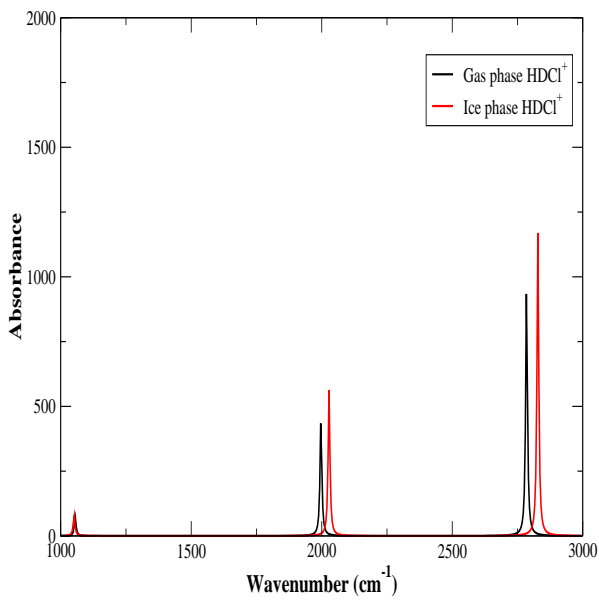

FIG. 6. - Infrared spectrum of $\mathrm{HDCl}^{+}$in gas as well as in ice phase.

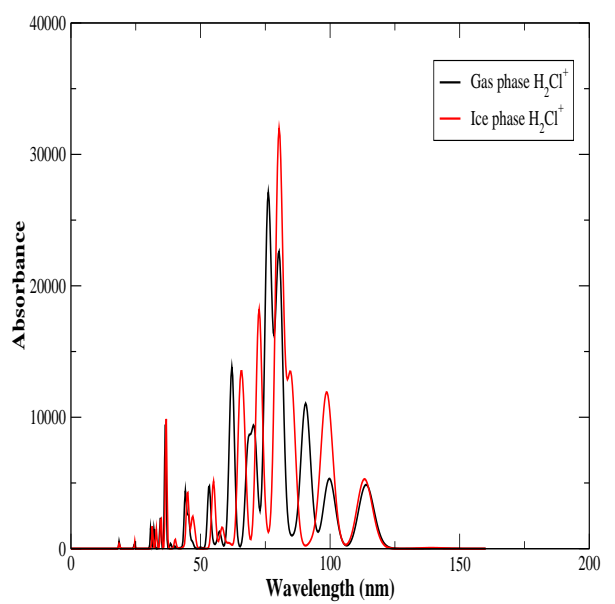

FIG. 7.- Electronic absorption spectrum of $\mathrm{H}_{2} \mathrm{Cl}^{+}$in gas phase and in ice phase.

tween the 3 to 9 bands of ALMA (84 - $720 \mathrm{GHz})$. Our computed column density also suggests that it could also be observed around the similar region, where $\mathrm{H}_{2} \mathrm{Cl}^{+}$was observed.

Different electronic absorption spectral parameters of $\mathrm{H}_{2} \mathrm{Cl}^{+}$in gas phase are given in Table 6 . In gas phase, the spectrum is characterized by five intense peaks at wavelengths of 90.6, 80.3, 76.1, 62.3, 36.4 nm (Fig. 7). These intense peaks are assigned due to HOMO-LUMO transitions. These transitions correspond to $\mathrm{H}-0 \rightarrow \mathrm{L}+2$, $\mathrm{H}-2 \rightarrow \mathrm{L}+0, \mathrm{H}-1 \rightarrow \mathrm{L}+3, \mathrm{H}-2 \rightarrow \mathrm{L}+2, \mathrm{H}-0 \rightarrow \mathrm{L}+13$. Depending on the composition of interstellar grain mantle, peak positions in ice phase are shifted. These features are presented in Table 6 with corresponding transition details. Fig. 7 clearly shows some differences in gas phase and ice phase electronic absorption spectra of $\mathrm{H}_{2} \mathrm{Cl}^{+}$.

\section{CONCLUSIONS}

Protonated hydrogen chloride or chloronium $\left(\mathrm{H}_{2} \mathrm{Cl}^{+}\right)$ ion has been recently identified towards Sgr A, W31C. In this paper, we investigated the existence and different aspects of its two isotopomers namely, $\mathrm{HDCl}^{+}$and $\mathrm{D}_{2} \mathrm{Cl}^{+}$. Following are the major results of this paper:

- Langevin theory and parameterized trajectory theory are used for the computation of various ion molecular reaction rates containing $\mathrm{H}_{2} \mathrm{Cl}^{+}$and its related species.

- Our chemical modeling shows that $\mathrm{HDCl}^{+}$could be efficiently formed in gas phase and emission line should be strong enough to be observed.

- We explored vibrational, rotational and electronic spectral properties of $\mathrm{H}_{2} \mathrm{Cl}^{+}, \mathrm{D}_{2} \mathrm{Cl}^{+}$and $\mathrm{HDCl}^{+}$in different astrophysical environments. Resulting chemical parameters could assist observers in identifying these molecules around Interstellar Molecular cloud. In Appendix A, we present a representative catalog files in JPL format for gas phase $\mathrm{HDCl}^{+}$which will be useful for observational purpose.

\section{ACKNOWLEDGMENTS}

Ankan Das is grateful to ISRO for financial support through a respond project (Grant No. ISRO/RES/2/372/11-12), SKC thank a DST project (Grant No.SR/S2/HEP-40/2008) and LM thank MOES for partial funding during this work. The authors would like to thank the anonymous referee whose valuable suggestions have helped to improve this paper significantly.

\section{REFERENCES}

Allamandola, L. J., Sandford S. A., Tielens A.G.G.M. 1992., APJ, 399, 134

Albertsson, T., Semenov, D. A., Vasyunin, A. I., Henning T., Herbst, E., 2013, APJS, 207, 27

Allen, M., Robinson, G. W., 1977., ApJ, 212, 396

Amin, M. Y. 1996, Earth Moon Planets, 73, 133

Asplund, M., Grevesse, N., Sauval, A. J., \& Scott, P. 2009, ARA \& A, 47, 481

Blake, G. A., Keene, J., \& Phillips, T. G. 1985, ApJ, 295, 501

Blake, G. A., Anicich, V. G., \& Huntress, W. T., Jr. 1986, ApJ, 300,415

Caselli, P., Stantcheva, T., Shalabiea, O., Shematovich, V. I. \& Herbst, E., 2002, P\&SS,50, 1257

Cazaux, S., Cobut, V., Marseille, M., Spaans, M., Caselli, P. 2010, A\&A, 522, 74

Chakrabarti, S., Chakrabarti, S.K., 2000a. A\&A 354, L6

Chakrabarti, S. K., Chakrabarti, S., 2000b. Ind. J. Phys 74B, 97

Chakrabarti, S.K., Das, A., Acharyya, K.,Chakrabarti, S., 2006, A\&A, 457, 167
Chakrabarti, S.K., Das, A., Acharyya, K.,Chakrabarti, S., 2006, BASI, 34, 299

Cuppen, H. M., Herbst, E., 2007, APJ, 668, 294

Cuppen, H. M., Van Dishoeck E., F., Herbst, E., Tielens, A. G. G. M., 2009, A\&A, 508, 275

Das, A., Chakrabarti, S. K., Acharyya K. \& Chakrabarti, S., 2008a, NEWA, 13, 457

Das, A., Acharyya, K., Chakrabarti, S. \& Chakrabarti, S. K.,2008b, A\&A, 486, 209

Das, A., Acharyya, K. \& Chakrabarti, S. K., 2010, MNRAS 409, 789

Das, A. \& Chakrabarti, S. K., 2011, 418. 545, MNRAS

Das, A., Majumdar, L., Chakrabarti, S. K., \& Chakrabarti S., 2013a, NEWA, 23, 118

Das, A., Majumdar, L., Chakrabarti, S. K., \& Saha, R., Chakrabarti, S., 2013b, MNRAS, 433, 3152

Dalgarno, A., de Jong, T., Oppenheimer, M., \& Black, J. H. 1974, ApJ, 192, L37

Draine, B. T. 1978, ApJS, 36, 595 
TABLE 4

Vibrational frequencies of DiffERent forms of Chloronium in GAS PHASE, IN WATER iCE AND IN MiXed ICE AT MP2/AUG-CC-PVQZ LEVEL OF THEORY

\begin{tabular}{|c|c|c|c|c|c|c|c|c|}
\hline Species & Charge & $\begin{array}{l}\text { Spin } \\
\text { state }\end{array}$ & $\begin{array}{c}\text { Peak } \\
\text { positions } \\
(\text { Gas phase }) \\
(\text { Wavenumber }) \\
\left(\text { in } \mathrm{cm}^{-1}\right)\end{array}$ & Absorbance & $\begin{array}{c}\text { Peak } \\
\text { positions } \\
\left(\mathrm{H}_{2} \mathrm{O} \text { ice }\right) \\
(\text { Wavenumber }) \\
\left({\left.\text { in } \mathbf{c m}^{-1}\right)}\right.\end{array}$ & Absorbance & $\begin{array}{c}\text { Peak } \\
\text { positions } \\
(\text { Mixed ice }) \\
(\text { Wavenumber }) \\
\left({\left.\text { in } \mathbf{c m}^{-1}\right)}\right.\end{array}$ & Absorbance \\
\hline $\mathbf{H}_{2} \mathrm{Cl}^{+}$ & Cation & Singlet & $\begin{array}{l}1213.01 \\
2779.83 \\
2789.60 \\
\end{array}$ & $\begin{array}{c}23.5567 \\
342.2380 \\
213.5581 \\
\end{array}$ & $\begin{array}{l}1208.84 \\
2822.06 \\
2834.00 \\
\end{array}$ & $\begin{array}{c}25.3066 \\
409.2761 \\
267.9801 \\
\end{array}$ & $\begin{array}{l}1209.44 \\
2818.33 \\
2831.03 \\
\end{array}$ & $\begin{array}{c}24.9379 \\
403.9254 \\
262.6758 \\
\end{array}$ \\
\hline $\mathrm{D}_{2} \mathrm{Cl}^{+}$ & Cation & Singlet & $\begin{array}{c}870.12 \\
1995.63 \\
1998.19 \\
\end{array}$ & $\begin{array}{c}8.0653 \\
164.4252 \\
100.4653 \\
\end{array}$ & $\begin{array}{c}866.89 \\
2025.45 \\
2030.55 \\
\end{array}$ & $\begin{array}{c}8.8043 \\
198.2665 \\
127.2815 \\
\end{array}$ & $\begin{array}{c}867.34 \\
2022.82 \\
2028.39 \\
\end{array}$ & $\begin{array}{c}8.6495 \\
195.5651 \\
124.6488 \\
\end{array}$ \\
\hline $\mathrm{HDCl}^{+}$ & Cation & Singlet & $\begin{array}{l}1055.58 \\
1996.92 \\
2784.69\end{array}$ & $\begin{array}{c}21.0134 \\
132.2521 \\
278.3963\end{array}$ & $\begin{array}{l}1051.30 \\
2027.98 \\
2828.05\end{array}$ & $\begin{array}{c}23.6298 \\
163.0641 \\
338.3961\end{array}$ & $\begin{array}{l}1051.20 \\
2025.58 \\
2824.70\end{array}$ & $\begin{array}{c}23.2953 \\
160.4419 \\
333.0264 \\
\end{array}$ \\
\hline
\end{tabular}

TABLE 5

Theoretical \& AVAilable Experimental rotational PARAMEters of Chloronium and its Different isotopomers at MP2/AUG-CC-PVQZ LEVEL OF THEORY

\begin{tabular}{|c|c|c|c|c|c|c|}
\hline Species & $\begin{array}{c}\text { Rotational } \\
\text { constants }\end{array}$ & $\begin{array}{l}\text { Values } \\
\text { in } \mathrm{MHz}\end{array}$ & $\begin{array}{c}\text { Experimental } \\
\text { values } \\
\text { in } \mathrm{MHz}^{a} \\
\end{array}$ & $\begin{array}{c}\text { Distortional } \\
\text { constants }\end{array}$ & $\begin{array}{l}\text { Values } \\
\text { in } \mathrm{MHz}\end{array}$ & $\begin{array}{c}\text { Experimental } \\
\text { values } \\
\text { in } \mathrm{MHz}^{a} \\
\end{array}$ \\
\hline $\mathbf{H}_{2} \mathrm{Cl}^{+}$in gas phase & $\begin{array}{l}\mathrm{A} \\
\mathrm{B} \\
\mathrm{C}\end{array}$ & $\begin{array}{l}336730.77093 \\
274941.86042 \\
151335.22094\end{array}$ & $\begin{array}{l}337353.229 \\
273586.425 \\
148100.004\end{array}$ & $\begin{array}{c}D_{J} \\
D_{J K} \\
D_{K} \\
d_{1} \\
d_{2}\end{array}$ & $\begin{array}{c}0.19899 \times 10^{2} \\
-0.73569 \times 10^{2} \\
0.12577 \times 10^{3} \\
-0.83773 \times 10^{1} \\
0.58014\end{array}$ & $\begin{array}{c}- \\
-71.814 \\
- \\
- \\
-\end{array}$ \\
\hline $\mathrm{HDCl}^{+}$in gas phase & $\begin{array}{l}\mathrm{A} \\
\mathrm{B} \\
\mathrm{C}\end{array}$ & $\begin{array}{l}309898.96477 \\
153561.70202 \\
102697.60073\end{array}$ & & $\begin{array}{c}D_{J} \\
D_{J K} \\
D_{K} \\
d_{1} \\
d_{2} \\
\end{array}$ & $\begin{array}{c}0.35636 \times 10^{1} \\
-0.92932 \times 10^{1} \\
0.98535 \times 10^{2} \\
-0.13938 \times 10^{1} \\
-0.11650\end{array}$ & \\
\hline $\mathrm{D}_{2} \mathrm{Cl}^{+}$in gas phase & $\begin{array}{l}\mathrm{A} \\
\mathrm{B} \\
\mathrm{C}\end{array}$ & $\begin{array}{c}177672.18281 \\
137566.23157 \\
77526.70474\end{array}$ & & $\begin{array}{c}D_{J} \\
D_{J K} \\
D_{K} \\
d_{1} \\
d_{2} \\
\end{array}$ & $\begin{array}{c}0.48691 \times 10^{1} \\
-0.17934 \times 10^{2} \\
0.33137 \times 10^{2} \\
-0.20906 \times 10^{1} \\
-0.81717 \times 10^{-1}\end{array}$ & \\
\hline
\end{tabular}

de Graauw, Th., Helmich F. P., Phillips, T. G., et al. 2010, A \& A, 518, L6

Emprechtinger, M., Caselli, P., Volgenau, N. H., Stutzki, J., Wiedner, M. C., 2008, A\&A, 493,89

Froebrich, D. 2005, ApJS, 156, 169

Federman, S. R., Cardell, J. A., van Dishoeck, E. F., Lambert, D. L., \& Black, , ApJ, 1995 445, 325

Foresman, J.B., Frisch, A., 1995-96, Exploring Chemistry with Electronic structure Gaussian, Inc., Pittsburgh, PA, 15106 USA

Glenewinkel-Meyer T., Ottinger, C., Rosmus, P., Werner, H-J, 1991, Chem. Phys. 152409

Herbst, E. 2006, in Springer Handbook of Atomic, Molecular, and Optical Physics, ed. G. W. F. Drake (New York: Springer), 561 Hasegawa, T.,Herbst, E., Leung, C.M., 1992, APJ, 82, 167

Jura, M. 1974, ApJ, 190, L33

Keane, J. V., Boogert, A. C. A., Tielens, A. G. G. M.,

Ehrenfreund, P., Schutte, W. A., 2001, A\&A, 375L, 43

Leitch-Devlin, M., A., Williams, D., A., 213, 295, MNRAS, 1985

Lis, D. C., Pearson, J. C., Neufeld, D. A., et al. 2010, A \& A, 521, L9

Linsky, J.L., Diplas, A., Wood, B.E., Brown, A., Ayres, T.R., Savage, B.D., 1995. ApJ. 451, 335B351

Majumdar, L., Das, A., Chakrabarti, S.K., Chakrabarti, S., 2013a, New Astronomy, 20, 15

Majumdar, L., Das, A., Chakrabarti, S.K., 2013b, A\&A (in press)

Majumdar, L., Das, A., Chakrabarti, S.K., Chakrabarti, S., 2012, Research in Astronomy \& Astrophysics, 12, 1613

Müller, H. S. P., unpublished result reported on The Cologne Database
Müller, H. S. P., Schloder, F., Stutzki, J., \& Winnewisser, G. 2005, J. Mol. Struct., 742, 215

Myers, P. C., Adams, F. C., Chen, H., et al. 1998, ApJ, 492, 703 Muller, H. S. P., Thorwirth, S., Roth, D. A., \& Winnewisser, G. 2001, A\&A, 370, L49

Neufeld, D. A., Goicoechea, J. R., Sonnentrucker, P., et al. 2010, A \& A, 521, L10

Neufeld, D. A., Wolfire, M. G. 2009, ApJ, 706, 1594

Neufeld, D. A., Roueff, E., Sbell, R. L. et al., 2012, ApJ, 748, 37

Pascual-Ahuir, J. L., Silla, E., Tun, I., J. Comp. Chem., 1994, 15 1127

Pickett, H. M., J. Mol. Spectrosc., 1991, 148, 371

Pilbratt, G. L., Riedinger, J. R., Passvogel, T., et al. 2010, A \& A, 518, L1

Puzzarini, C., Stanton, J. F., Gauss, J.,2010, International Review in Physical Chemistry, 29,2,273

Roberts, H., Millar, T. J., 2000, A\&A, 361, 388

Salez, M., Frerking, M. A., \& Langer, W. D. 1996, ApJ, 467, 708

Saito, S., Yamamoto, S., 1988, J. Chem. Phys., 88, 2281

Schilke, P., Phillips, T. G., \& Wang, N. 1995, ApJ, 441, 334

Shalabiea, O. M., Greenberg, J. M., 1994, A\&A, 290, 266

Smith, M. 1998, Ap\&SS, 261, 169

Sonnentrucker, P., Neufeld, D. A., Phillips, T. G., et al. 2010, A\&A, 521, L12

Stantcheva, T., Shematovich, V. I., Herbst, E., 2002, A\&A, 391, 1069

Su, T., \& Chesnavich, W. J. 1982, J. Chem. Phys., 76, 5183

Tomasi, J., Cammi, R., Mennucci, B., Cappelli, C., and Corni, S., Phys. Chem. Chem. Phys., 2002, 4, 5697 
TABLE 6

Electronic transitions of $\mathrm{H}_{2} \mathrm{CL}^{+}$AT B3LYP/6-311++G** LeVEL of theORY

\begin{tabular}{|c|c|c|c|c|c|}
\hline Species & Wavelength in $\mathrm{nm}$ & Absorbance & 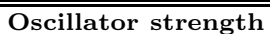 & Transitions & Contribution in \% \\
\hline \multirow{14}{*}{$\mathrm{H}_{2} \mathrm{Cl}^{+}$in gas phase } & 113.9 & 4864.07 & 0.1201 & $\mathrm{H}-1 \rightarrow \mathrm{L}+0$ & 98 \\
\hline & 99.7 & 5322.96 & 0.1316 & $\mathrm{H}-1 \rightarrow \mathrm{L}+1$ & 90 \\
\hline & 90.6 & 11062.41 & 0.2728 & $\mathrm{H}-0 \rightarrow \mathrm{L}+2$ & 100 \\
\hline & 80.3 & 22614.49 & 0.5051 & $\mathrm{H}-2 \rightarrow \mathrm{L}+0$ & 66 \\
\hline & 76.1 & 27125.91 & 0.4172 & $\mathrm{H}-1 \rightarrow \mathrm{L}+3$ & 70 \\
\hline & 70.8 & 9307.55 & 0.211 & $\mathrm{H}-2 \rightarrow \mathrm{L}+1$ & 57 \\
\hline & 62.3 & 13154.01 & 0.2709 & $\mathrm{H}-2 \rightarrow \mathrm{L}+2$ & 90 \\
\hline & 57.3 & 1301.54 & 0.03 & $\mathrm{H}-0 \rightarrow \mathrm{L}+9$ & 100 \\
\hline & 53.3 & 4644.87 & 0.1117 & $\mathrm{H}-1 \rightarrow \mathrm{L}+8$ & 96 \\
\hline & 44.2 & 4413.36 & 0.1047 & $\mathrm{H}-2 \rightarrow \mathrm{L}+9$ & 90 \\
\hline & 36.4 & 9444.575 & 0.2395 & $\mathrm{H}-0 \rightarrow \mathrm{L}+13$ & 100 \\
\hline & 34.5 & 2347.95 & 0.0594 & $\mathrm{H}-1 \rightarrow \mathrm{L}+13$ & 98 \\
\hline & 32.09 & 1508.80 & 0.0205 & $\mathrm{H}-3 \rightarrow \mathrm{L}+10$ & 100 \\
\hline & 30.79 & 1549.00 & 0.0402 & $\mathrm{H}-3 \rightarrow \mathrm{L}+10$ & 100 \\
\hline \multirow{14}{*}{$\mathrm{H}_{2} \mathrm{Cl}^{+}$in ice phase } & 113.3 & 5297.52 & 0.1308 & $\mathrm{H}-1 \rightarrow \mathrm{L}+0$ & 98 \\
\hline & 98.1 & 11706.04 & 0.513 & $\mathrm{H}-0 \rightarrow \mathrm{L}+2$ & 97 \\
\hline & 80.3 & 31995.46 & 0.7694 & $\mathrm{H}-2 \rightarrow \mathrm{L}+0$ & 66 \\
\hline & 72.6 & 18217.29 & 0.4457 & $\mathrm{H}-2 \rightarrow \mathrm{L}+1$ & 83 \\
\hline & 65.1 & 13505.80 & 0 & $\mathrm{H}-2 \rightarrow \mathrm{L}+4$ & 74 \\
\hline & 58.4 & 1618.54 & 0.0381 & $\mathrm{H}-0 \rightarrow \mathrm{L}+9$ & 100 \\
\hline & 55.0 & 4755.99 & 0.1215 & $\mathrm{H}-1 \rightarrow \mathrm{L}+8$ & 96 \\
\hline & 46.8 & 2349.30 & 0.0526 & $\mathrm{H}-2 \rightarrow \mathrm{L}+8$ & 91 \\
\hline & 45.2 & 4262.98 & 0 & $\mathrm{H}-2 \rightarrow \mathrm{L}+11$ & 100 \\
\hline & 40.21 & 697.86 & 0.018 & $\mathrm{H}-2 \rightarrow \mathrm{L}+12$ & 48 \\
\hline & 36.7 & 9872.20 & 0.2521 & $\mathrm{H}-0 \rightarrow \mathrm{L}+13$ & 100 \\
\hline & 34.7 & 2272.75 & 0.065 & $\mathrm{H}-1 \rightarrow \mathrm{L}+13$ & 99 \\
\hline & 32.9 & 1495.5532 & 0.0207 & $\mathrm{H}-3 \rightarrow \mathrm{L}+11$ & 100 \\
\hline & 31.4 & 1707.95 & 0.0437 & $\mathrm{H}-3 \rightarrow \mathrm{L}+12$ & 82 \\
\hline \multirow{8}{*}{$\mathrm{H}_{2} \mathrm{Cl}^{+}$in mixed ice } & 113.5 & 5344.97 & 0.1321 & $\mathrm{H}-1 \rightarrow \mathrm{L}+0$ & 98 \\
\hline & 99.4 & 206.40 & 0.1575 & $\mathrm{H}-1 \rightarrow \mathrm{L}+1$ & 92 \\
\hline & 80.3 & 31849.63 & 0.7566 & $\mathrm{H}-2 \rightarrow \mathrm{L}+0$ & 63 \\
\hline & 72.6 & 18544.85 & 0.4527 & $\mathrm{H}-2 \rightarrow \mathrm{L}+1$ & 82 \\
\hline & 65.7 & 13565.30 & 0 & $\mathrm{H}-2 \rightarrow \mathrm{L}+5$ & 100 \\
\hline & 58.4 & 1616.83 & 0.0388 & $\mathrm{H}-0 \rightarrow \mathrm{L}+9$ & 100 \\
\hline & 54.9 & 4785.04 & 0.1193 & $\mathrm{H}-1 \rightarrow \mathrm{L}+8$ & 96 \\
\hline & 36.7 & 9833.04 & 0.2511 & $\mathrm{H}-0 \rightarrow \mathrm{L}+13$ & 100 \\
\hline
\end{tabular}

Tomasi, J., Mennucci, B., Cammi, R., Chem. Rev., 2005, 105, 2999

Tomasi, J., Mennucci, B., Cancs, E., J. Mol. Struct. (Theochem), 1999, 464, 211

van Dishoeck, E. F., \& Black, J. H. 1986, ApJS, 62, 109
Woon, D. E., Herbst, E., 2009, APJS, 185, 273

Woodall, J., Agndez, M., Markwick-Kemper, A.J., Millar, T.J., 2007, A\&A, 466, 1197

Zmuidzinas, J., Blake, G. A., Carlstrom, J., et al. 1995, ApJ, 447, L125 


\section{Appendix-A}

Existence of interstellar Chloronium ion has recently been reported by Herschel Space Observatory's Heterodyne Instrument for Far-Infrared (Neufeld et al. 2012). Our calculations show that one of the deuterated forms of choloronium ion $\left(\mathrm{HDCl}^{+}\right)$is significantly abundant and should be observed. In order to summarize results of our computation on rotational spectroscopy, we prepare our spectral information for $\mathrm{HDCl}^{+}$(Table A1 in the format of JPL catalog) to assist its detection around the ISM. In Table A1, the computed rotational transitions for the gas phase $\mathrm{HDCl}^{+}$is shown. This Table is prepared with our calculated values of spectroscopic constants which are given in Table 5. In Table A1, we have given the rotational transitions in $\mathrm{MHz}$ unit. Corresponding intensity of lines are tabulated in $\mathrm{nm}^{2} \mathrm{MHz}$ unit. Intensity of any line represents absorption cross section over spectral line shape (calculated at $300 \mathrm{~K}$ and tabulated in base 10 logarithm unit). Other parameters which are responsible for the computation of line frequencies are given at footnote of Table A1. 
Table A1: Different rotational transitions and its related parameters for gas phase $\mathrm{HDCl}^{+}$in the format of JPL catalog.

\begin{tabular}{|c|c|c|c|c|c|c|c|c|c|}
\hline Frequency $^{a}$ & Uncertainty $^{b}$ & $\mathbf{I}^{c}$ & $\mathbf{D}^{d}$ & $\mathbf{E}_{\text {lower }}{ }^{e}$ & $\mathbf{g}_{u p}^{f}$ & $\mathbf{T a g}^{g}$ & $\mathbf{Q n F}^{h}$ & $\mathbf{Q n}_{u p}{ }^{i}$ & $\mathbf{Q n}_{\text {lower }^{j}}$ \\
\hline 257376.1993 & 0.0000 & -2.8248 & 3 & -0.0000 & 4 & 38001 & 335 & 1010122 & $\begin{array}{llllll}0 & 0 & 0 & 2 & 1\end{array}$ \\
\hline 257376.1993 & 0.0000 & -2.4316 & 3 & -0.0000 & 4 & 38001 & 335 & 10122 & $\begin{array}{lllll}0 & 0 & 0 & 2 & 2\end{array}$ \\
\hline 257376.1993 & 0.0000 & -2.8248 & 3 & -0.0000 & 4 & 38001 & 335 & 10122 & $\begin{array}{llllll}0 & 0 & 0 & 2 & 1\end{array}$ \\
\hline 257376.1993 & 0.0000 & -2.7830 & 3 & -0.0000 & 4 & 38001 & 335 & $\begin{array}{llll}1 & 0 & 1 & 22\end{array}$ & $\begin{array}{llllll}0 & 0 & 0 & 2 & 3\end{array}$ \\
\hline 257376.2326 & 0.0000 & -2.7797 & 3 & -0.0000 & 6 & 38001 & 335 & $\begin{array}{lllll}1 & 0 & 1 & 2 & 3\end{array}$ & $\begin{array}{lllll}0 & 0 & 0 & 2 & 2\end{array}$ \\
\hline 257376.2326 & 0.0000 & -2.0650 & 3 & -0.0000 & 6 & 38001 & 335 & $\begin{array}{lllll}1 & 0 & 1 & 2 & 3\end{array}$ & $\begin{array}{llllll}0 & 0 & 0 & 2 & 3\end{array}$ \\
\hline 257376.2592 & 0.0000 & -2.7200 & 3 & -0.0000 & 2 & 38001 & 335 & $\begin{array}{lllll}1 & 0 & 1 & 2 & 1\end{array}$ & $\begin{array}{llllll}0 & 0 & 0 & 2 & 1\end{array}$ \\
\hline 257376.2592 & 0.0000 & -2.8187 & 3 & -0.0000 & 2 & 38001 & 335 & $\begin{array}{llll}1012 & 1\end{array}$ & 00022 \\
\hline 257386.0031 & 0.0000 & -2.2865 & 3 & -0.0000 & 4 & 38001 & 335 & 10132 & $\begin{array}{llllll}0 & 0 & 0 & 2 & 1\end{array}$ \\
\hline 257386.0031 & 0.0000 & -2.7946 & 3 & -0.0000 & 4 & 38001 & 335 & 101332 & $\begin{array}{lllll}0 & 0 & 0 & 2 & 2\end{array}$ \\
\hline 257386.0031 & 0.0000 & -4.1421 & 3 & -0.0000 & 4 & 38001 & 335 & 10132 & $\begin{array}{lllll}0 & 0 & 0 & 2 & 3\end{array}$ \\
\hline 257386.0181 & 0.0000 & -1.8634 & 3 & -0.0000 & 8 & 38001 & 335 & 10134 & $\begin{array}{lllll}0 & 0 & 0 & 2 & 3\end{array}$ \\
\hline 257386.0529 & 0.0000 & -2.0650 & 3 & -0.0000 & 6 & 38001 & 335 & $\begin{array}{lllll}1 & 0 & 1 & 3 & 3\end{array}$ & $\begin{array}{lllll}0 & 0 & 0 & 2 & 2\end{array}$ \\
\hline 257386.0529 & 0.0000 & -2.7796 & 3 & -0.0000 & 6 & 38001 & 335 & $\begin{array}{lllll}1 & 0 & 1 & 3 & 3\end{array}$ & $\begin{array}{lllll}0 & 0 & 0 & 2 & 3\end{array}$ \\
\hline 257393.8667 & 0.0000 & -2.8187 & 3 & -0.0000 & 2 & 38001 & 335 & $\begin{array}{lllll}1 & 0 & 1 & 1 & 1\end{array}$ & $\begin{array}{llllll}0 & 0 & 0 & 2 & 1\end{array}$ \\
\hline 257393.8667 & 0.0000 & -2.7199 & 3 & -0.0000 & 2 & 38001 & 335 & $\begin{array}{lllll}10 & 0 & 1 & 1\end{array}$ & $\begin{array}{lllll}0 & 0 & 0 & 2 & 2\end{array}$ \\
\hline 257393.8669 & 0.0000 & -3.7450 & 3 & -0.0000 & 4 & 38001 & 335 & 101112 & $\begin{array}{llllll}0 & 0 & 0 & 2 & 1\end{array}$ \\
\hline 257393.8669 & 0.0000 & -2.2901 & 3 & -0.0000 & 4 & 38001 & 335 & $\begin{array}{lllll}10 & 1 & 1 & 2\end{array}$ & $\begin{array}{lllll}0 & 0 & 0 & 2 & 3\end{array}$ \\
\hline 257393.8670 & 0.0000 & -2.8123 & 3 & -0.0000 & 4 & 38001 & 335 & 10112 & 000022 \\
\hline 514659.8572 & 0.0000 & -6.7938 & 3 & 8.5857 & 4 & 38001 & 335 & 202032 & $\begin{array}{lllll}1 & 0 & 1 & 1 & 1\end{array}$ \\
\hline 514659.8824 & 0.0000 & -7.4094 & 3 & 8.5857 & 6 & 38001 & 335 & 20233 & 10112 \\
\hline 514666.8692 & 0.0000 & -3.1365 & 3 & 8.5857 & 2 & 38001 & 335 & $\begin{array}{lllll}2 & 0 & 2 & 2 & 1\end{array}$ & $\begin{array}{lllll}10 & 1 & 12\end{array}$ \\
\hline 514666.8694 & 0.0000 & -1.7143 & 3 & 8.5857 & 6 & 38001 & 335 & 202233 & 10112 \\
\hline 514666.8695 & 0.0000 & -2.2435 & 3 & 8.5857 & 2 & 38001 & 335 & 20221 & $\begin{array}{lllll}1 & 0 & 1 & 1 & 1\end{array}$ \\
\hline 514666.8696 & 0.0000 & -2.2437 & 3 & 8.5857 & 4 & 38001 & 335 & 20222 & $\begin{array}{lllll}10 & 1 & 1 & 2\end{array}$ \\
\hline 514666.8698 & 0.0000 & -2.1448 & 3 & 8.5857 & 4 & 38001 & 335 & 20222 & $\begin{array}{lllll}1 & 0 & 1 & 1 & 1\end{array}$ \\
\hline 514667.6710 & 0.0000 & -2.8243 & 3 & 8.5855 & 4 & 38001 & 335 & $\begin{array}{lllll}2 & 0 & 2 & 3 & 2\end{array}$ & $\begin{array}{lllll}1 & 0 & 1 & 3 & 3\end{array}$ \\
\hline 514667.6788 & 0.0000 & -2.8208 & 3 & 8.5855 & 8 & 38001 & 335 & 202334 & $\begin{array}{lllll}1 & 0 & 1 & 3 & 3\end{array}$ \\
\hline 514667.6964 & 0.0000 & -1.9589 & 3 & 8.5855 & 6 & 38001 & 335 & 20233 & 10133 \\
\hline 514667.7136 & 0.0000 & -1.7698 & 3 & 8.5855 & 8 & 38001 & 335 & 202234 & $\begin{array}{lllll}1 & 0 & 1 & 3 & 4\end{array}$ \\
\hline 514667.7208 & 0.0000 & -2.1126 & 3 & 8.5855 & 4 & 38001 & 335 & 20232 & $\begin{array}{lllll}10 & 1 & 32\end{array}$ \\
\hline 514667.7313 & 0.0000 & -2.8220 & 3 & 8.5855 & 6 & 38001 & 335 & 20233 & $\begin{array}{lllll}10 & 1 & 3 & 4\end{array}$ \\
\hline 514667.7463 & 0.0000 & -2.8260 & 3 & 8.5855 & 6 & 38001 & 335 & 20233 & 10132 \\
\hline 514669.6441 & 0.0000 & -5.4590 & 3 & 8.5857 & 6 & 38001 & 335 & 20243 & 10112 \\
\hline 514674.6834 & 0.0000 & -3.6631 & 3 & 8.5855 & 6 & 38001 & 335 & $\begin{array}{lllll}2 & 0 & 2 & 2 & 3\end{array}$ & $\begin{array}{lllll}1 & 0 & 1 & 3 & 3\end{array}$ \\
\hline 514674.6836 & 0.0000 & -2.8877 & 3 & 8.5855 & 4 & 38001 & 335 & $\begin{array}{lllll}2 & 0 & 2 & 2 & 2\end{array}$ & 10133 \\
\hline 514674.7183 & 0.0000 & -2.6833 & 3 & 8.5855 & 6 & 38001 & 335 & 20223 & 10134 \\
\hline 514674.7331 & 0.0000 & -3.1158 & 3 & 8.5855 & 2 & 38001 & 335 & $\begin{array}{lllll}2 & 0 & 2 & 2 & 1\end{array}$ & $\begin{array}{lllll}1 & 0 & 1 & 3 & 2\end{array}$ \\
\hline 514674.7332 & 0.0000 & -4.5605 & 3 & 8.5855 & 6 & 38001 & 335 & $\begin{array}{lllll}2 & 0 & 2 & 2 & 3\end{array}$ & 10132 \\
\hline 514674.7334 & 0.0000 & -3.5845 & 3 & 8.5855 & 4 & 38001 & 335 & 20222 & 10132 \\
\hline 514676.6697 & 0.0000 & -1.8438 & 3 & 8.5857 & 4 & 38001 & 335 & 202212 & 10112 \\
\hline 514676.6698 & 0.0000 & -1.9425 & 3 & 8.5857 & 2 & 38001 & 335 & $\begin{array}{lllll}2 & 0 & 2 & 1 & 1\end{array}$ & 10112 \\
\hline 514676.6699 & 0.0000 & -1.9425 & 3 & 8.5857 & 4 & 38001 & 335 & 20212 & $\begin{array}{lllll}1 & 0 & 1 & 1 & 1\end{array}$ \\
\hline 514676.6700 & 0.0000 & -2.8364 & 3 & 8.5857 & 2 & 38001 & 335 & $\begin{array}{lllll}2 & 0 & 2 & 1 & 1\end{array}$ & $\begin{array}{lllll}1 & 0 & 1 & 1 & 1\end{array}$ \\
\hline 514677.4582 & 0.0000 & -2.3000 & 3 & 8.5855 & 6 & 38001 & 335 & 20243 & 10133 \\
\hline 514677.4648 & 0.0000 & -1.7918 & 3 & 8.5851 & 4 & 38001 & 335 & $\begin{array}{lllll}2 & 0 & 2 & 3 & 2\end{array}$ & $\begin{array}{lllll}1 & 0 & 1 & 2 & 1\end{array}$ \\
\hline 514677.4913 & 0.0000 & -3.6483 & 3 & 8.5851 & 4 & 38001 & 335 & 202322 & 10123 \\
\hline 514677.4930 & 0.0000 & -4.0096 & 3 & 8.5855 & 6 & 38001 & 335 & 20243 & 10134 \\
\hline 514677.4991 & 0.0000 & -1.3636 & 3 & 8.5851 & 8 & 38001 & 335 & 202234 & $\begin{array}{lllll}1 & 0 & 1 & 2 & 3\end{array}$ \\
\hline 514677.5064 & 0.0000 & -1.1122 & 3 & 8.5855 & 10 & 38001 & 335 & 20245 & 10134 \\
\hline 514677.5080 & 0.0000 & -1.3848 & 3 & 8.5855 & 6 & 38001 & 335 & 20243 & $\begin{array}{lllll}1 & 0 & 1 & 3 & 2\end{array}$ \\
\hline 514677.5167 & 0.0000 & -2.2922 & 3 & 8.5851 & 6 & 38001 & 335 & $\begin{array}{lllll}2 & 0 & 2 & 3 & 3\end{array}$ & $\begin{array}{lllll}1 & 0 & 1 & 2 & 3\end{array}$ \\
\hline 514677.5172 & 0.0000 & -1.2463 & 3 & 8.5855 & 8 & 38001 & 335 & 20244 & 10133 \\
\hline 514677.5246 & 0.0000 & -2.2754 & 3 & 8.5851 & 4 & 38001 & 335 & $\begin{array}{lllll}2 & 0 & 2 & 3 & 2\end{array}$ & $\begin{array}{lllll}1 & 0 & 1 & 2 & 2\end{array}$ \\
\hline 514677.5500 & 0.0000 & -1.5647 & 3 & 8.5851 & 6 & 38001 & 335 & $\begin{array}{lllll}2 & 0 & 2 & 3 & 3\end{array}$ & 10122 \\
\hline 514677.5521 & 0.0000 & -2.2942 & 3 & 8.5855 & 8 & 38001 & 335 & 20244 & 10134 \\
\hline 514684.4770 & 0.0000 & -2.3423 & 3 & 8.5851 & 2 & 38001 & 335 & $\begin{array}{lllll}2 & 0 & 2 & 2 & 1\end{array}$ & $\begin{array}{lllll}1 & 0 & 1 & 2 & 1\end{array}$ \\
\hline 514684.4773 & 0.0000 & -2.4262 & 3 & 8.5851 & 4 & 38001 & 335 & 20222 & $\begin{array}{lllll}1 & 0 & 1 & 2 & 1\end{array}$ \\
\hline 514684.4837 & 0.0000 & -7.6805 & 3 & 8.5855 & 4 & 38001 & 335 & 20212 & $\begin{array}{lllll}1 & 0 & 1 & 3 & 3\end{array}$ \\
\hline 514684.5037 & 0.0000 & -1.6815 & 3 & 8.5851 & 6 & 38001 & 335 & 20223 & 10123 \\
\hline 514684.5039 & 0.0000 & -2.4062 & 3 & 8.5851 & 4 & 38001 & 335 & 20222 & 10123 \\
\hline 514684.5335 & 0.0000 & -6.3471 & 3 & 8.5855 & 4 & 38001 & 335 & $\begin{array}{lllll}2 & 0 & 2 & 1 & 2\end{array}$ & $\begin{array}{lllll}1 & 0 & 1 & 3 & 2\end{array}$ \\
\hline 514684.5337 & 0.0000 & -7.0346 & 3 & 8.5855 & 2 & 38001 & 335 & $\begin{array}{lllll}2 & 0 & 2 & 1 & 1\end{array}$ & 10132 \\
\hline 514684.5368 & 0.0000 & -2.4322 & 3 & 8.5851 & 2 & 38001 & 335 & $\begin{array}{lllll}2 & 0 & 2 & 2 & 1\end{array}$ & 10122 \\
\hline 514684.5370 & 0.0000 & -2.4096 & 3 & 8.5851 & 6 & 38001 & 335 & 202233 & $\begin{array}{lllll}1 & 0 & 1 & 2 & 2\end{array}$ \\
\hline 514684.5372 & 0.0000 & -2.0557 & 3 & 8.5851 & 4 & 38001 & 335 & 20222 & 10122 \\
\hline 514687.2785 & 0.0000 & -5.8721 & 3 & 8.5851 & 6 & 38001 & 335 & 20243 & $\begin{array}{llll}10 & 1 & 2 & 3\end{array}$ \\
\hline 514687.3117 & 0.0000 & -6.2690 & 3 & 8.5851 & 6 & 38001 & 335 & 20243 & 10122 \\
\hline 514687.3375 & 0.0000 & -7.5999 & 3 & 8.5851 & 8 & 38001 & 335 & 20244 & 10123 \\
\hline 514694.2775 & 0.0000 & -3.8539 & 3 & 8.5851 & 4 & 38001 & 335 & $\begin{array}{lllll}2 & 0 & 2 & 1 & 2\end{array}$ & $\begin{array}{lllll}1 & 0 & 1 & 2 & 1\end{array}$ \\
\hline 514694.2776 & 0.0000 & -2.9352 & 3 & 8.5851 & 2 & 38001 & 335 & $\begin{array}{lllll}2 & 0 & 2 & 1 & 1\end{array}$ & $\begin{array}{lllll}1 & 0 & 1 & 2 & 1\end{array}$ \\
\hline 514694.3040 & 0.0000 & -2.4123 & 3 & 8.5851 & 4 & 38001 & 335 & 20212 & 10123 \\
\hline 514694.3373 & 0.0000 & -2.9434 & 3 & 8.5851 & 4 & 38001 & 335 & 20212 & $\begin{array}{lllll}1 & 0 & 1 & 2 & 2\end{array}$ \\
\hline 514694.3374 & 0.0000 & -2.8496 & 3 & 8.5851 & 2 & 38001 & 335 & $\begin{array}{lllll}2 & 0 & 2 & 1 & 1 \\
\end{array}$ & $\begin{array}{lllll}10 & 122 \\
\end{array}$ \\
\hline
\end{tabular}




\begin{tabular}{|c|c|c|c|c|c|c|c|c|c|}
\hline Frequency $^{a}$ & Uncertainty $^{b}$ & $\mathbf{I}^{c}$ & $\mathbf{D}^{d}$ & $\mathbf{E}_{\text {lower }}{ }^{e}$ & $\mathbf{g}_{u p}{ }^{f}$ & Tag $^{g}$ & $\mathrm{QnF}^{h}$ & $\mathbf{Q n}_{u p}{ }^{i}$ & $\mathbf{Q n}_{\text {lower }}{ }^{j}$ \\
\hline 771769.9945 & 0.0000 & -7.6046 & 3 & 25.7535 & 6 & 38001 & 335 & $\begin{array}{llllll}3 & 0 & 3 & 4 & 3\end{array}$ & 200212 \\
\hline 771774.5695 & 0.0000 & -6.9643 & 3 & 25.7535 & 4 & 38001 & 335 & $\begin{array}{lllll}3 & 0 & 3 & 3 & 2\end{array}$ & $\begin{array}{lllll}2 & 0 & 2 & 1 & 1\end{array}$ \\
\hline 771774.5696 & 0.0000 & -6.7153 & 3 & 25.7535 & 4 & 38001 & 335 & $\begin{array}{lllll}3 & 0 & 3 & 3 & 2\end{array}$ & 20212 \\
\hline 771776.9609 & 0.0000 & -2.9249 & 3 & 25.7533 & 6 & 38001 & 335 & 30343 & 20244 \\
\hline 771776.9716 & 0.0000 & -2.9289 & 3 & 25.7533 & 10 & 38001 & 335 & 30345 & 20244 \\
\hline 771777.0070 & 0.0000 & -1.7710 & 3 & 25.7533 & 8 & 38001 & 335 & 30344 & 20244 \\
\hline 771777.0173 & 0.0000 & -1.6427 & 3 & 25.7533 & 10 & 38001 & 335 & 30345 & 20245 \\
\hline 771777.0200 & 0.0000 & -1.8814 & 3 & 25.7533 & 6 & 38001 & 335 & $\begin{array}{lllll}30 & 34 & \end{array}$ & 20243 \\
\hline 771777.0527 & 0.0000 & -2.9291 & 3 & 25.7533 & 8 & 38001 & 335 & $\begin{array}{lllll}30 & 3 & 4 & 4\end{array}$ & 20245 \\
\hline 771777.0661 & 0.0000 & -2.9252 & 3 & 25.7533 & 8 & 38001 & 335 & $\begin{array}{lllll}30 & 3 & 4 & 4\end{array}$ & $\begin{array}{lllll}2 & 0 & 2 & 4 & 3\end{array}$ \\
\hline 771779.7946 & 0.0000 & -8.0545 & 3 & 25.7532 & 6 & 38001 & 335 & $\begin{array}{lllll}30 & 3 & 4 & 3\end{array}$ & $\begin{array}{lllll}2 & 0 & 2 & 2 & 2\end{array}$ \\
\hline 771779.7948 & 0.0000 & -5.5854 & 3 & 25.7532 & 6 & 38001 & 335 & $\begin{array}{lllll}30 & 3 & 4 & 3\end{array}$ & $\begin{array}{lllll}2 & 0 & 2 & 2 & 3\end{array}$ \\
\hline 771779.8409 & 0.0000 & -6.5020 & 3 & 25.7532 & 8 & 38001 & 335 & $\begin{array}{lllll}30 & 3 & 4 & 4\end{array}$ & $\begin{array}{lllll}2 & 0 & 2 & 2 & 3\end{array}$ \\
\hline 771781.5480 & 0.0000 & -4.2055 & 3 & 25.7533 & 8 & 38001 & 335 & $\begin{array}{lllll}3 & 0 & 3 & 3 & 4\end{array}$ & 20244 \\
\hline 771781.5754 & 0.0000 & -3.0578 & 3 & 25.7533 & 6 & 38001 & 335 & $\begin{array}{lllll}3 & 0 & 3 & 3 & 3\end{array}$ & 20244 \\
\hline 771781.5937 & 0.0000 & -2.9173 & 3 & 25.7533 & 8 & 38001 & 335 & $\begin{array}{lllll}30 & 3 & 3 & 4\end{array}$ & 20245 \\
\hline 771781.5952 & 0.0000 & -3.2034 & 3 & 25.7533 & 4 & 38001 & 335 & $\begin{array}{lllll}3 & 0 & 3 & 3 & 2\end{array}$ & 202433 \\
\hline 771781.6070 & 0.0000 & -7.8321 & 3 & 25.7533 & 8 & 38001 & 335 & $\begin{array}{lllll}3 & 0 & 3 & 3 & 4\end{array}$ & 202433 \\
\hline 771781.6345 & 0.0000 & -3.9561 & 3 & 25.7533 & 6 & 38001 & 335 & $\begin{array}{lllll}3 & 0 & 3 & 3 & 3\end{array}$ & $\begin{array}{lllll}2 & 0 & 2 & 4 & 3\end{array}$ \\
\hline 771784.3550 & 0.0000 & -1.6817 & 3 & 25.7535 & 2 & 38001 & 335 & $\begin{array}{lllll}3 & 0 & 3 & 2 & 1\end{array}$ & $\begin{array}{lllll}2 & 0 & 2 & 1 & 1\end{array}$ \\
\hline 771784.3551 & 0.0000 & -2.5820 & 3 & 25.7535 & 2 & 38001 & 335 & $\begin{array}{lllll}3 & 0 & 3 & 2 & 1\end{array}$ & $\begin{array}{lllll}2 & 0 & 2 & 1 & 2\end{array}$ \\
\hline 771784.3698 & 0.0000 & -1.9214 & 3 & 25.7532 & 4 & 38001 & 335 & $\begin{array}{lllll}3 & 0 & 3 & 3 & 2\end{array}$ & $\begin{array}{lllll}2 & 0 & 2 & 2 & 2\end{array}$ \\
\hline 771784.3699 & 0.0000 & -3.2816 & 3 & 25.7532 & 4 & 38001 & 335 & $\begin{array}{lllll}3 & 0 & 3 & 3 & 2\end{array}$ & $\begin{array}{lllll}2 & 0 & 2 & 2 & 3\end{array}$ \\
\hline 771784.3701 & 0.0000 & -1.4255 & 3 & 25.7532 & 4 & 38001 & 335 & $\begin{array}{lllll}3 & 0 & 3 & 3 & 2\end{array}$ & $\begin{array}{lllll}2 & 0 & 2 & 2 & 1\end{array}$ \\
\hline 771784.3817 & 0.0000 & -1.1519 & 3 & 25.7535 & 6 & 38001 & 335 & $\begin{array}{lllll}3 & 0 & 3 & 2 & 3\end{array}$ & 202212 \\
\hline 771784.3818 & 0.0000 & -0.9989 & 3 & 25.7532 & 8 & 38001 & 335 & $\begin{array}{lllll}3 & 0 & 3 & 3 & 4\end{array}$ & $\begin{array}{lllll}2 & 0 & 2 & 2 & 3\end{array}$ \\
\hline 771784.4091 & 0.0000 & -1.1980 & 3 & 25.7532 & 6 & 38001 & 335 & $\begin{array}{lllll}3 & 0 & 3 & 3 & 3\end{array}$ & $\begin{array}{lllll}2 & 0 & 2 & 2 & 2\end{array}$ \\
\hline 771784.4092 & 0.0000 & -1.9191 & 3 & 25.7532 & 6 & 38001 & 335 & $\begin{array}{lllll}30 & 3 & 3 & 3\end{array}$ & $\begin{array}{lllll}2 & 0 & 2 & 2 & 3\end{array}$ \\
\hline 771784.4147 & 0.0000 & -1.5815 & 3 & 25.7535 & 4 & 38001 & 335 & $\begin{array}{lllll}3 & 0 & 3 & 2 & 2\end{array}$ & $\begin{array}{lllll}2 & 0 & 2 & 1 & 1\end{array}$ \\
\hline 771784.4149 & 0.0000 & -1.6789 & 3 & 25.7535 & 4 & 38001 & 335 & $\begin{array}{lllll}3 & 0 & 3 & 2 & 2\end{array}$ & 202212 \\
\hline 771786.7559 & 0.0000 & -2.0839 & 3 & 25.7533 & 8 & 38001 & 335 & $\begin{array}{lllll}3 & 0 & 3 & 5 & 4\end{array}$ & 20244 \\
\hline 771786.7817 & 0.0000 & -2.0168 & 3 & 25.7529 & 6 & 38001 & 335 & $\begin{array}{lllll}3 & 0 & 3 & 4 & 3\end{array}$ & $\begin{array}{lllll}2 & 0 & 2 & 3 & 3\end{array}$ \\
\hline 771786.7994 & 0.0000 & -3.6919 & 3 & 25.7529 & 6 & 38001 & 335 & $\begin{array}{lllll}30 & 3 & 4 & 3\end{array}$ & $\begin{array}{lllll}2 & 0 & 2 & 3 & 4\end{array}$ \\
\hline 771786.8016 & 0.0000 & -3.9953 & 3 & 25.7533 & 8 & 38001 & 335 & $\begin{array}{lllll}3 & 0 & 3 & 5 & 4\end{array}$ & 20245 \\
\hline 771786.8072 & 0.0000 & -1.1157 & 3 & 25.7529 & 6 & 38001 & 335 & $\begin{array}{lllll}30 & 3 & 4 & 3\end{array}$ & 202332 \\
\hline 771786.8101 & 0.0000 & -0.8416 & 3 & 25.7529 & 10 & 38001 & 335 & 30345 & 202234 \\
\hline 771786.8131 & 0.0000 & -0.6956 & 3 & 25.7533 & 12 & 38001 & 335 & 30356 & 20245 \\
\hline 771786.8150 & 0.0000 & -0.8996 & 3 & 25.7533 & 8 & 38001 & 335 & 30354 & 202433 \\
\hline 771786.8180 & 0.0000 & -0.7969 & 3 & 25.7533 & 10 & 38001 & 335 & 30355 & 20244 \\
\hline 771786.8278 & 0.0000 & -0.9754 & 3 & 25.7529 & 8 & 38001 & 335 & $\begin{array}{lllll}3 & 0 & 3 & 4 & 4\end{array}$ & $\begin{array}{lllll}2 & 0 & 2 & 3 & 3\end{array}$ \\
\hline 771786.8455 & 0.0000 & -2.0349 & 3 & 25.7529 & 8 & 38001 & 335 & 30344 & 202234 \\
\hline 771786.8637 & 0.0000 & -2.0790 & 3 & 25.7533 & 10 & 38001 & 335 & 30355 & 202245 \\
\hline
\end{tabular}


Majumdar et al.

\begin{tabular}{|c|c|c|c|c|c|c|c|c|c|}
\hline Frequency $^{a}$ & Uncertainty $^{b}$ & $\mathbf{I}^{c}$ & $\mathbf{D}^{d}$ & $\mathbf{E}_{\text {lower }}{ }^{e}$ & $\mathbf{g}_{u p}{ }^{f}$ & $\operatorname{Tag}^{g}$ & $\mathbf{Q n F}^{h}$ & $\mathbf{Q \mathbf { n } _ { u p } { } ^ { i }}$ & $\mathbf{Q n}_{\text {lower }}{ }^{j}$ \\
\hline 7771789.5897 & 0.0000 & $\begin{array}{c}-5.6801 \\
\end{array}$ & $\overline{3}$ & 25.7532 & 8 & 38001 & 335 & $\begin{array}{lllll}3 & 0 & 3 & 5 & 4\end{array}$ & 2002223 \\
\hline 771791.3481 & 0.0000 & -7.9628 & 3 & 25.7533 & 6 & 38001 & 335 & $\begin{array}{llll}3 & 0 & 3 & 23\end{array}$ & 20244 \\
\hline 771791.3569 & 0.0000 & -2.5796 & 3 & 25.7529 & 4 & 38001 & 335 & $\begin{array}{lllll}3 & 0 & 3 & 3 & 2\end{array}$ & 20233 \\
\hline 771791.3688 & 0.0000 & -2.5801 & 3 & 25.7529 & 8 & 38001 & 335 & $\begin{array}{llll}3 & 0 & 3 & 3\end{array}$ & 20233 \\
\hline 771791.3823 & 0.0000 & -1.8579 & 3 & 25.7529 & 4 & 38001 & 335 & 30332 & 20232 \\
\hline 771791.3864 & 0.0000 & -1.5198 & 3 & 25.7529 & 8 & 38001 & 335 & $\begin{array}{llll}3 & 0 & 3 & 34\end{array}$ & 20234 \\
\hline 771791.3962 & 0.0000 & -1.7203 & 3 & 25.7529 & 6 & 38001 & 335 & $\begin{array}{llll}3 & 0 & 3 & 33\end{array}$ & 20233 \\
\hline 771791.4072 & 0.0000 & -6.1028 & 3 & 25.7533 & 6 & 38001 & 335 & $\begin{array}{llll}3 & 0 & 3 & 23\end{array}$ & 20243 \\
\hline 771791.4139 & 0.0000 & -2.5763 & 3 & 25.7529 & 6 & 38001 & 335 & $\begin{array}{llll}3 & 0 & 3 & 3\end{array}$ & 20234 \\
\hline 771791.4216 & 0.0000 & -2.5746 & 3 & 25.7529 & 6 & 38001 & 335 & $\begin{array}{llll}3 & 0 & 3 & 3\end{array}$ & 20232 \\
\hline 771791.4404 & 0.0000 & -6.5360 & 3 & 25.7533 & 4 & 38001 & 335 & $\begin{array}{llll}3 & 0 & 3222\end{array}$ & 20243 \\
\hline 771794.1552 & 0.0000 & -2.3814 & 3 & 25.7532 & 2 & 38001 & 335 & $\begin{array}{lllll}3 & 0 & 3 & 2 & 1\end{array}$ & 20222 \\
\hline 771794.1556 & 0.0000 & -2.2746 & 3 & 25.7532 & 2 & 38001 & 335 & $\begin{array}{lllll}3 & 0 & 3 & 2 & 1\end{array}$ & 20221 \\
\hline 771794.1818 & 0.0000 & -2.3459 & 3 & 25.7532 & 6 & 38001 & 335 & $\begin{array}{llll}3 & 0 & 3 & 23\end{array}$ & 20222 \\
\hline 771794.1820 & 0.0000 & -1.6244 & 3 & 25.7532 & 6 & 38001 & 335 & $\begin{array}{llll}3 & 0 & 3 & 23\end{array}$ & 20223 \\
\hline 771794.2150 & 0.0000 & -1.9990 & 3 & 25.7532 & 4 & 38001 & 335 & $\begin{array}{llll}3 & 0 & 3 & 22\end{array}$ & 20222 \\
\hline 771794.2152 & 0.0000 & -2.3452 & 3 & 25.7532 & 4 & 38001 & 335 & $\begin{array}{llll}3 & 0 & 3 & 22\end{array}$ & 20223 \\
\hline 771794.2153 & 0.0000 & -2.3801 & 3 & 25.7532 & 4 & 38001 & 335 & $\begin{array}{lllll}3 & 0 & 3 & 22\end{array}$ & $\begin{array}{lllll}2 & 0 & 2 & 2 & 1\end{array}$ \\
\hline 771796.5767 & 0.0000 & -6.7671 & 3 & 25.7529 & 8 & 38001 & 335 & 30354 & 20233 \\
\hline 771796.5944 & 0.0000 & -6.3778 & 3 & 25.7529 & 8 & 38001 & 335 & 30354 & 20234 \\
\hline 771796.6565 & 0.0000 & -7.5460 & 3 & 25.7529 & 10 & 38001 & 335 & 30355 & 202334 \\
\hline 771801.1678 & 0.0000 & -3.1604 & 3 & 25.7529 & 2 & 38001 & 335 & $\begin{array}{lllll}3 & 0 & 3 & 2 & 1\end{array}$ & 202232 \\
\hline 771801.1689 & 0.0000 & -3.6539 & 3 & 25.7529 & 6 & 38001 & 335 & $\begin{array}{llll}3 & 0 & 3 & 23\end{array}$ & 20233 \\
\hline 771801.1866 & 0.0000 & -2.7452 & 3 & 25.7529 & 6 & 38001 & 335 & $\begin{array}{llll}3 & 0 & 3 & 23\end{array}$ & 20234 \\
\hline 771801.1944 & 0.0000 & -5.1289 & 3 & 25.7529 & 6 & 38001 & 335 & $\begin{array}{llll}3 & 0 & 3 & 23\end{array}$ & 20232 \\
\hline 771801.2021 & 0.0000 & -2.9559 & 3 & 25.7529 & 4 & 38001 & 335 & $\begin{array}{llll}3 & 0 & 3 & 22\end{array}$ & 20233 \\
\hline 771801.2276 & 0.0000 & -3.6855 & 3 & 25.7529 & 4 & 38001 & 335 & $\begin{array}{llll}3 & 0 & 3 & 22\end{array}$ & 20232 \\
\hline & $\begin{array}{r}{ }^{b} \mathrm{Ca} \\
\text { in units of } \\
{ }^{c} \text { Base } 10 \\
{ }^{d} \mathrm{D} \\
(0 \text { for a } \\
{ }^{e} \text { Lov } \\
\text { is the spin s } \\
\text { QnF }=10 \\
\text { numbers for each } \\
\text { Qmod5, the } \mathrm{r} \\
\text { qu }\end{array}$ & $\begin{array}{l}\text { ees of fre } \\
\text { ns, } 2 \text { for } \\
\text { state en } \\
\text { level } \\
\text { per state } \\
\text { istical w } \\
\\
\text { Coding } \\
\times Q+10 \\
\text { ate; H ir } \\
\text { dual whe } \\
\text { um num } \\
{ }^{i} \text { Quan } \\
{ }^{j} \text { Quar }\end{array}$ & $\begin{array}{l}\text { or th } \\
\times \text { H } \\
\text { dicat } \\
\text { a Q } \\
\text { ers } \\
\text { um n } \\
\text { um }\end{array}$ & $\begin{array}{l}\text { ty of the } \\
\text { tegrated i } \\
\text { the rotat } \\
\text { holecules, } \\
\mathrm{cm}^{-1} \text { rela } \\
\text { ground vil } \\
\text { racy : } \mathrm{g}_{u p} \\
\mathrm{~g}_{N}=2 I \\
\text { Molecule } \\
\text { ormat of } \\
N_{Q n} ; \mathrm{N}_{Q} \\
\text { the numb } \\
\text { livided by } \\
\text { thout the } \\
\text { nbers for } \\
\text { mbers for }\end{array}$ & $\begin{array}{l}\text { for } \mathrm{n} \\
\text { ve to } \\
\text { ionic } \\
=g_{I} \times \\
+1 \text { th } \\
\text { g } \\
\text { lantur } \\
\text { is the } \\
\text { of ha } \\
\text {, give } \\
\text { gin de } \\
\text { he upp } \\
\text { he low }\end{array}$ & $\begin{array}{l}\text { ater or } \\
300 \mathrm{~K} \\
\text { ition } \mathrm{f} \\
\text { linear } \\
\text { lowes } \\
\text { te. } \\
\mathrm{v} \text {, whe } \\
\text { otatio } \\
\text { umber } \\
\text { mber } \\
\text { nteger } \\
\text { he nun } \\
\text { nating } \\
\text { state } \\
\text { state }\end{array}$ & $\begin{array}{l}\text { ion is } \\
\text { qual to } \\
\mathrm{nm}^{2} \mathrm{~N} \\
\text { ction } \\
\text { lecules } \\
\text { nergy } \\
\mathrm{g}_{I} \\
\text { I degen } \\
\text { quantu } \\
\text { uantum } \\
\text { er of pr } \\
\text { les) }\end{array}$ & $\begin{array}{l}\text { acy. } \\
\text { umbers; } \\
\text { ipal }\end{array}$ & \\
\hline
\end{tabular}

